\title{
Life cycle engineering of lightweight structures
}

Herrmann, Christoph; Dewulf, Wim; Hauschild, Michael; Kaluza, Alexander; Kara, Sami; Skerlos, Steve

Published in:

C I R P Annals

Link to article, DOI:

10.1016/j.cirp.2018.05.008

Publication date:

2018

Document Version

Peer reviewed version

Link back to DTU Orbit

Citation (APA):

Herrmann, C., Dewulf, W., Hauschild, M., Kaluza, A., Kara, S., \& Skerlos, S. (2018). Life cycle engineering of lightweight structures. C I R P Annals, 67(2), 651-672. https://doi.org/10.1016/j.cirp.2018.05.008

\section{General rights}

Copyright and moral rights for the publications made accessible in the public portal are retained by the authors and/or other copyright owners and it is a condition of accessing publications that users recognise and abide by the legal requirements associated with these rights.

- Users may download and print one copy of any publication from the public portal for the purpose of private study or research.

- You may not further distribute the material or use it for any profit-making activity or commercial gain

- You may freely distribute the URL identifying the publication in the public portal

If you believe that this document breaches copyright please contact us providing details, and we will remove access to the work immediately and investigate your claim. 
Life cycle engineering of lightweight structures

Christoph Herrmann (2) ${ }^{a, \star}$, Wim Dewulf $(2)^{b}$, Michael Hauschild (1) ${ }^{c}$, Alexander Kaluza ${ }^{a}$, Sami Kara (1) ${ }^{d}$, Steve Skerlos ${ }^{e}$

${ }^{a}$ Chair of Sustainable Manufacturing and Life Cycle Engineering, Institute of Machine Tools and Production Technology (IWF), Technische Universität Braunschweig, Braunschweig, Germany

${ }^{\mathrm{b}}$ Department of Mechanical Engineering, KU Leuven, Belgium

${ }^{c}$ Department of Management Engineering, Technical University of Denmark, Kongens Lyngby, Denmark

d School of Mechanical \& Manufacturing Engineering, The University of New South Wales, Sydney, Australia

${ }^{\mathrm{e}}$ Department of Mechanical Engineering, University of Michigan, Ann Arbor, USA

*Corresponding author, e-mail address: c.herrmann@tu-braunschweig.de.

Abstract

Lightweight structures are increasingly necessary to meet current engineering requirements. Weight reduction in diverse applications such as automobiles or machine tools is achieved either by using less material or by substituting material with a lighter one, which provides more functionality per unit of weight. To be an effective enabler for sustainability, lightweight structures should result in lower environmental impacts per functional unit when compared to conventional structures on a life cycle basis. However, applying new materials and manufacturing processes often leads to an increase in environmental impacts from the raw materials and production stage of the life cycle. Furthermore, end-of-life disassembly and recycling may become more difficult. In addition, the expected efficiency gains from the use of lightweight structures depend on how the overall market and technical systems respond to them. Consequently, the environmental evaluation of lightweight structures in engineering entails various methodological challenges. Organised around a life cycle engineering framework with a focus on eco-effectiveness, this paper provides a comprehensive review of lightweight structure applications and the challenges and opportunities they present in a life cycle engineering context.

Keywords: Life cycle, Methodology, Lightweight structures

1. Introduction

Lightweight structures are physical products or parts of products that enable a required technical functionality at lower weight than generally achievable by other means. This can be implemented by using less material or by providing more functionality or improved functionality through lighter structures [1]. The relationship between technical performance and weight can be described in a number of ways, including the stiffness-to-weight ratio, which is a central concept in engineering design.

Traditionally, two main drivers have motivated the introduction of lightweight structures. From a technical point of view, lighter products can enable better performance, such as in the case of higher acceleration of a vehicle (e.g. an airplane) or providing a competitive advantage in sporting equipment (e.g. a golf club). Lighter products can also reduce life cycle cost because of lower operation cost for many applications. Depending on the specific case, material and production cost could either decrease by using less material or increase due to higher embodied energies and innovative, comparably inefficient production technologies. Furthermore, lighter products can be a means to comply with regulation. For instance, lighter vehicles enable to reduce fuel consumption and lead to decreased penalty fees for vehicle manufacturers faced with corporate average fuel requirements.

The authors aim to provide a review on the status quo and to anticipate future research regarding lightweight structures from a life cycle engineering perspective. According to Hauschild et al., life cycle engineering (LCE) is part of a company's activity covering engineering methods to look "at products [ . . . ] over all stages of the life cycle(s)" [2]. As a result, LCE is concerned with all "the main activities and life cycle stages (product development, raw material extraction, manufacturing, after-sales service/engineering, reuse, remanufacturing, recycling and disposal)" [2].
Lightweight structures are typically a part of larger product systems, e.g. as a structural element of a vehicle or machine tool. Those products operate in a background system such as a certain region with a specific local electricity mix (see Fig. 1). 


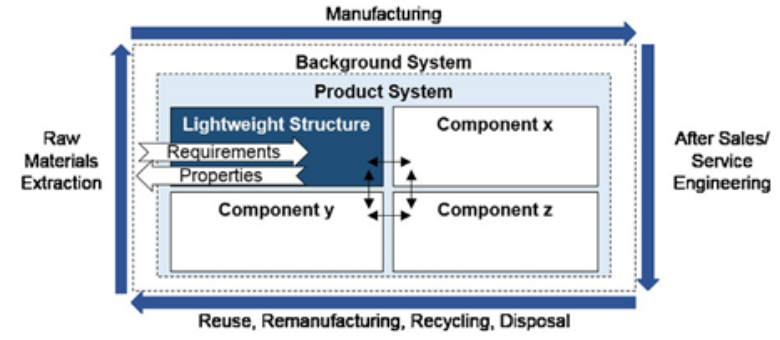

Fig. 1. Lightweight structures as part of product systems.

Thus, in addition to the different life cycle stages, on the one hand interdependencies between different sub-systems or components need to be considered when analysing potential burdens and benefits regarding the sustainability of lightweight structures. This way, properties of lightweight structures, such as their mass, are evaluated in context of a system perspective. On the other hand, both the product- and the background system set requirements for lightweight structures. The average lifetime of a product, for example, should align with technical capabilities of lightweight structures.

Hereafter, foundational concepts in life cycle engineering are presented and set into the context of lightweight structures in order to promote comprehension of specific challenges.

\subsection{Evolution of life cycle engineering}

An early definition of life cycle engineering was given by Alting: "Life cycle engineering is the art of designing the product life cycle through choices about product concept, structure, materials and processes, and life cycle assessment (LCA) is the tool that visualizes the environmental and resource consequences of these choices" [3]. In the CIRP Encyclopedia, Jeswiet broadens the scope to all three pillars of sustainability, defining life cycle engineering as: "[ . . . ] engineering activities, which include the application of technological and scientific principles to manufacturing products with the goal of protecting the environment, conserving resources, encouraging economic progress, keeping in mind social concerns, and the need for sustainability, while optimising the product life cycle and minimizing pollution and waste" [4].

This understanding has led to a significant eco-efficiency improvement in developing products and technologies. However, the benefits gained as a result of eco-efficiency improvements may have wiped out due to population and affluence increase and the associated environmental footprint. In the meantime, the concept of sustainability has shifted from relative to absolute sustainability due to the limited carrying capacity of the planet. As a result, Hauschild et al. propose a new life cycle engineering framework that combines a top-down with a bottom up perspective [2]. The framework enables a better understanding of the pressure that life cycle engineered products place on the earth's life support system. Sustainability constitutes an absolute constraint and is evaluated with regard to the time span of human civilisation. The top-down approach aligns with the different factors of the IPAT equation. The equation expresses the total environmental impact $(I)$ as the product of population $(P)$, affluence $(A)$ and the environmental impact caused by technology $(\mathrm{T})$. As global population and affluence have been steadily increasing and are expected to increase further, pressure mounts on the technological factor. The IPAT equation illustrates that, to use the example of climate change, greenhouse gas emissions (I) from the different life cycle stages of products $(T)$ must decrease by almost a factor of 10 by the middle of this century compared to 2010 [2]. Focusing on the technology factor of the IPAT equation, impact mitigation options include reducing energy demand, improving energy efficiency and shifting towards renewable energy. Improving efficiency reduces resource consumption as well as emissions to water, air and land, all of which increase stress on humans and natural systems. Furthermore, materials entering production need to be taken into account, as the extraction and processing of resources also require energy and potentially result in various direct environmental impacts. Assembly methods and joining techniques employed in creating products also require consideration, as they often determine the viability of recycling and (re-)processing options which may reduce environmental impacts.

In line with this understanding, Hauschild et al. redefined life cycle engineering as "[ . . . ] sustainability-oriented product development activities within the scope of one to several product life cycles. The methods and tools used in life cycle engineering must support reducing the total environmental impact associated with technology change and volume increase from one product generation to another, in order to ensure that new product technologies stay within their environmental space as derived from the planetary boundaries" [2].

As already highlighted in Alting's early definition of LCE, the assessment tool that helps engineers to quantify the environmental impacts of engineering decisions is life cycle assessment (LCA). A set of international standards prescribe the fundamental principles and framework of LCA [5,6]. Fig. 2 shows an LCA-based framework of LCE rooted in the ISO 14040 norms. Reasons to use LCA and an LCAbased engineering approach for lightweight structures are:

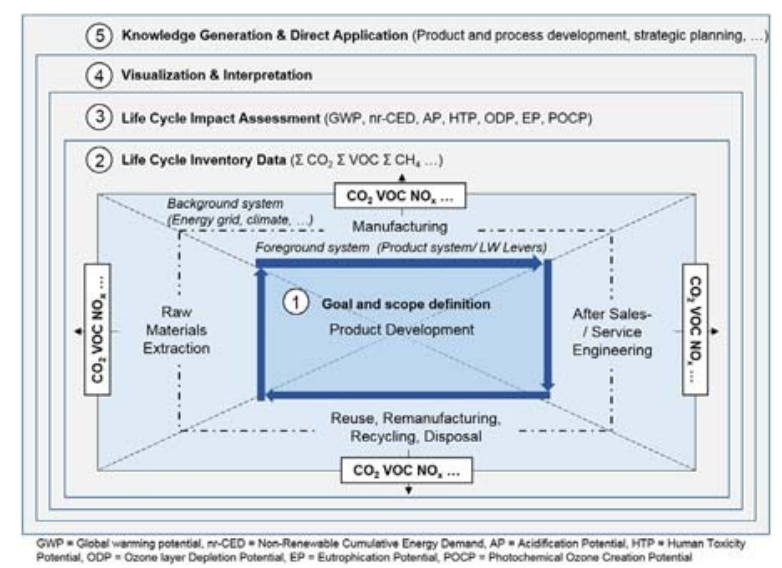

Fig. 2. Life cycle assessment methodology according to ISO 14040 as part of the bottom-up life cycle engineering methodology.

- Identify hotspots: Performing an LCA to support LCE allows for analysing the technosphere encompassing all life cycle stages and identifying the system elements with the most significant impacts on the ecosphere.

- Avoid burden shifting: Reducing the weight of a product is often motivated by a decrease in energy required to move it, thus decreasing its environmental impact (mostly during operation). However, this effect might be overcompensated by an increased impact of the raw material extraction, production and end-of-life stage.

- Identify trade-offs: Additional trade-offs may arise between different environmental impact categories. A reduction in climate change affecting emission during the use stage might be accompanied by substances with human toxicity potential being emitted in the raw materials extraction and manufacturing stage.

- Gain system understanding and build knowledge: Overall, LCE of lightweight structures fosters the understanding of cause-effect relationships and deepens knowledge on product- and process development. Thus, the most promising lightweight measures can be selected and options to reduce environmental impacts can be elaborated. 
The following paragraphs focus on a discussion of special considerations with regard to the methodological phases $(1-5)$ of an LCA-based LCE (Fig. 2) applicable to lightweight structures.

\subsubsection{Goal and scope definition}

The definition of goal and scope serves as a foundation for any LCAbased method. The system definition includes specifying the foreground and background systems ( 1 in 1 Fig. 2)

Within the foreground system, one needs to consider the type and mass of materials involved as well as manufacturing processes and direct effects on the use stage and end-of-life, for instance as summarized by Geyer for the case of automotive material substitution [7]. Regarding background systems, temporal and spatial differences can strongly influence the life cycle impacts of lightweight structures. This is especially the case for structures with a long lifetime [8]. If the use stage extends several years into the future, e.g. progress in the development of fuel technologies needs to be taken into account using appropriate forecasting methods. In practice, data availability for relevant background systems may be limited. Studies point out that a cut-off in certain background systems is necessary due to a lack of available information within these systems [9]. Fig. 3 summarizes relevant parameters in the foreground- and background systems for evaluating lightweight automotive components at the engineering design stage.

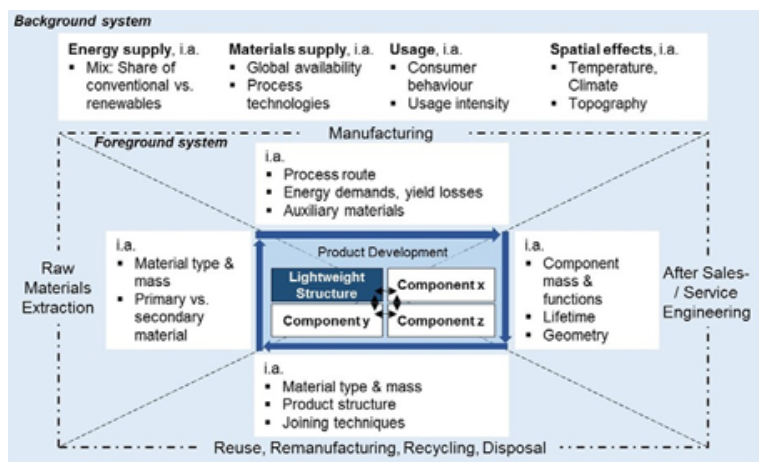

Fig. 3. Foreground and background system in LCA of lightweight structures; adapted from Ref. [11].

Depending on the goal of the study, an attributional or a consequential perspective may be adopted. An attributional perspective uses an accounting approach, which ascribes the product system to the share of the impacts of its processes that corresponds to its share in the use of the processes. A consequential perspective, in contrast, attempts to model the consequences of the decision being analysed. This involves an analysis of the expected market response when the decision is implemented to identify the technologies that will be affected by the decision [10]

\subsubsection{Life cycle inventory data}

The environmental assessment of lightweight structures over their whole life cycle requires the acquisition of both qualitative and quantitative data (see 2 in Fig. 2). This data is then used to populate a life cycle inventory model encompassing all relevant material- and energy flows. Within the raw materials extraction stage, this may include the extraction and processing of ores and the manufacturing of semi-finished products. The subsequent manufacturing stage contains all material- and energy flows of the manufacturing processes employed in production. During the use stage of lightweight structures, appropriate methods and tools allow the capture of the relationship between product mass and use phase resource consumption and emissions. Data acquisition for the endof-life requires knowledge of available treatment routes and technologies - which may be employed in an unknown location at an unknown point in time - as well as of the respective material input- and output flows of the available processes. Examples of dynamic and potentially important long-lived technologies are systems for power generation (providing energy to electrical vehicles) and sorting- and recovery systems for recycling of lightweight materials. The former is scheduled to undergo a major decarbonising process during the coming decades. For the latter, progress in the development of recycling technologies - particularly that of fibrereinforced composites - may be anticipated against the background of the Circular Economy Action Plan of the European Union [12].

\subsubsection{Life cycle impact assessment}

Impact assessment involves the interpretation of information gathered on elementary flows in the life cycle inventory using model-based flow-specific characterisation factors. These factors quantify the impacts associated with energy and material flows (see 3 in Fig 2). For vehicle systems, regulatory requirements are usually limited to the use stage and have a strong focus on greenhouse gas (GHG) emissions. However, for a study aimed at complying with the ISO 14040 standard, the selected impact categories need to be representative of the environmental impacts of the studied system [6] and not only focus on greenhouse gas emission during the use phase. For non-greenhouse gas impact categories, a deep understanding of the impact pathway is required. For instance, for impact categories such as freshwater use or acidification, environmental sensitivity may vary stronglyamong regions. This needs to be taken into account in the impact characterisation in order to accurately depict the environmental impact of lightweight structures [13]. This requires that the impact assessment makes use of an inventory which has not been aggregated beyond the level of individual processes, so as to keep the information such as the location of raw material extraction and emission. Raugei et al. assess different automotive lightweight structures with respect to their impact on use stage fuel consumption, primary energy generation, depletion of non-renewable energy resources, emission of greenhouse and acidifying gases as well as metal mining and refining operations [14]. Within this study, non-renewable cumulative energy demand (nr-CED), acidification potential (AP), and human toxicity potential (HTP) are identified as particularly relevant impact categories [14]. Bovea and Gallardo discuss the influence of different weighted impact assessment methods on a material selection case and point out the importance of a sensitivity analysis [15], which constitutes an integral part of the interpretation phase and the basis of the repeated iterations when conducting an LCA [16].

\subsubsection{Visualisation and interpretation}

The interpretation phase of an LCA (4 in Fig. 2) aims at identifying the issues that significantly influence the final results. These issues can be related to any or all of the previous phases (1-3 in Fig. 2), for example the assumptions made as part of the goal and scope definition or the characterisation factors used in the impact assessment. Results can and should be evaluated regarding their completeness, sensitivity and consistency. Many lightweight applications are associated with complex system interdependencies (see Fig. 3). Here, visualization can be helpful to analyse the benefits and trade-offs related to lightweight structures. A high quality LCA interpretation effort will include acombination within a multi-criteria solution space. Often results are depicted as multiple single criteria interpretations. This results either in the presentation of a quantitative listing or the provision of a large set of graphs. While providing a high degree of detailed information, this does not sufficiently support decision making $[17,18]$. Instead, advanced visualisation techniques could help to understand complex system interdependencies [19]. Another approach is the simplification of impact assessment results. It may be achieved either by focusing on one or only few impact categories or by aggregating certain relevant impacts, as discussed in Ref. [20]. 


\subsubsection{Knowledge generation and direct application}

The final stage of an LCA-based LCE methodology (see 5 in Fig. 2) covers the generation of knowledge and its direct application to improve existing and future products and processes. As LCE supports systems thinking as well as understanding and involves the handling of a large amount of data and results, the following aspects of knowledge generation and application should be considered:

- The results of an LCA and the knowledge derived from it need to be available and accessible at the right time and place to support management and engineering decisions (referred to as "the logistics of LCA knowledge").

- The existing LCA knowledge needs to be applied and further expanded, thus supporting the development of new products, processes and business models (referred to as "the management of LCA knowledge").

Data and parameters from past LCA studies can be used to estimate data and parameters for foreground and background systems in the early stage of product and process development.

\subsection{Scope and structure of the paper}

Lightweight structures have an impact on technical performance and production cost as well as on the environment [1,21]. A more holistic engineering approach for lightweight structures would permit intentional trade-offs between technical, economic, and environmental targets.

With respect to a strong sustainability definition, the aim of this paper is to review the relevant research regarding the environmentally oriented LCE of lightweight structures and to derive trends and needs for future research and development. Developing lightweight structures that have not been examined yet from an LCE perspective is not the focus. Section 2 provides an overview of levers to realise lightweight structures with respect to life cycle engineering. We further discuss the application of lightweight structures for automotive, aerospace and machine tool purposes. Other applications such as building structures are not part of the review. Within Sections 3-6, relevant approaches focusing on individual stages of the life cycle are studied: raw material processing (Section 3), manufacturing (Section 4), usage (Section 5), and end-of-life (Section 6). Examples and case studies are presented to highlight the importance of a life cycle perspective and the role of a quantitative assessment of potential environmental impacts. As LCE of lightweight structures involves large amounts of data and different models, methods and tools that support the engineering process need to be developed accordingly. This involves the modelling of product systems in different tool environments as well as the interpretation of complex results, which are discussed as part of each section. Section 7 proposes a synthesis based on research needs established by the previous sections and derives future research directions.

\section{Lightweight levers, application fields and review overview}

Lightweight structures are the result of systematic processes involving different engineering disciplines ranging from production engineering to product design and material science. In general, different lightweight levers, or leverage points, can be identified. The relevance of those levers strongly depends on the application.

\subsection{Lightweight levers and influences on life cycle engineering}

Different lightweight levers to design and manufacture lightweight structures can be distinguished (A-E). With respect to the product life cycle the end-of-life stage has to be included as well $(F)$. The lightweight levers are presented in the order of their chronological appearance within the review:
A. The application of lightweight materials. Material substitution approaches are widely used in lightweight structures. Typical lightweight materials include aluminium, magnesium, titanium or composites, e.g. fibre-reinforced polymers (FRP). They may be joined together in multi-material, laminar layers to form so-called "sandwich structures".

B. Form \& topology optimisation results in a load-case specific material allocation within a structure, thus substantially decreasing the weight per provided functionality. Lattice structures, which are a special form of topology-optimised structures, serve as an example here. The form and topology of lightweight structures need to be chosen in accordance with the applied materials.

C. Process technology is required to enable the manufacturing of lightweight structures. Specific topologies require the application of new processes (e.g. additive manufacturing for cellular structures). Large volume production with new materials (e.g. carbon fibrereinforced polymers in automotive applications) can only be enabled through effective and efficient process technologies.

D. The application of strategies A-C enable secondary (or indirect) lightweight benefits. When reducing the weight of a component (e.g. a car body), related components (e.g. brakes, suspension) can be made lighter as well, which in turn fosters further weight reduction (weight spiral).

E. Constraints set boundary conditions for the technological performance of technical systems. In certain cases, constraints allow for lighter structures, for example when setting vehicle weight restrictions for bridges.

F. Lightweight structures can pose new challenges regarding the end-of-life. As opposed to the other levers, this potentially causes negative effects on the environmental life cycle impacts of lightweight structures. In contrast to established recycling processes (e.g. recycling of steel), recycling technologies for new materials lack maturity (e.g. recycling of fibre-reinforced plastics), leading to a down-cycling of the materials. In addition, the energy required to recycle lightweight structures can be higher than for conventional materials (e.g. for the sorting and separation of composites). However, secondary materials have a much lower embodied energy compared to primary materials.

\subsection{Application fields}

Lightweight structures are of major relevance in different fields of application. To reduce energy consumption in the transport sector, lightweight design is considered a high priority. Helms and Lambrecht analysed potential global primary energy savings by lightweight design with respect to different transport modes [22]. Lightweight structures applied to passenger cars and light-duty vehicles show the highest energy saving potential due to the high market share of those vehicles (see Fig. 4) [22].

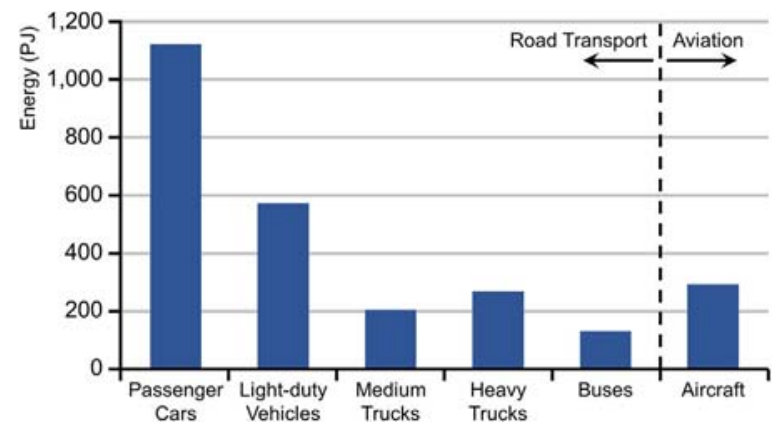

Fig. 4. Potential global annual primary energy savings by light-weighting in transportation, adapted from Ref. [22]. 
Applying lightweight structures to aircrafts has been identified as having the third highest energy saving potential. Weight reduction of aircrafts also allows the amount of fuel to be carried to be reduced, leading to further weight and fuel reduction (weight spiral) [22]. While rail vehicles and ships have less global energy saving potential, lightweight design for these transport modes should not be considered irrelevant. For instance, a study by Schmidt and Watson indicates a major effect of weight decrease for ferries, as the draft and thus the drag of a ship is reduced [23]. Other relevant applications encompass buildings and civil infrastructure as well as manufacturing equipment. In the case of buildings and civil infrastructure, lightweight structures are introduced with respect to material efficiency, construction efforts, and use stage constraints $[24,25]$. For manufacturing equipment use stage constraints as well as energy and material efficiency are the focus [26-28]. The application of lightweight structures in automotive, aerospace and machine tool contexts is elaborated in the following sections

\subsubsection{Automotive}

The average weight of passenger vehicles has increased in the past decades due to demanding requirements regarding comfort and safety. As a consequence, vehicle power output has increased, and so has the weight of the powertrain [22,29]. Recently, stricter requirements regarding use stage emissions have been set in the major markets for automotive manufacturers. One example is the EU directive 443/2009. Thus, among other measures, manufacturers have decreased vehicle weights for recent vehicle generations in EU.

In large-scale automotive manufacturing, lightweight structures have mainly been implemented using advanced designs based on steel. This includes new alloys, topologies as well as adapted manufacturing processes [30]. One example is the introduction of shell designs instead of frame constructions. These are enabled through the use of stamping and welding, which still represents the state-of-the art for large-scale manufacturing [1]. Recent innovations include the application of high-strength and ultra-high strength steels [30,31] as well as new manufacturing processes like tailor-rolled blanks [32].

In the past decades, the automotive material mix has shifted towards an increased usage of polymers and FRP (see Fig. 5) [33]. Another trend are interior applications such as dashboards, airbags and electronics that are also a driver for the usage of copper, as shown in Ref. [34]. The application of new materials in structural components of the car body, as for example shown by Goede et al. [35], is yet another approach. Kim et al. and Dhingra et al. discuss lightweight components as part of drivetrains [36,37]. The extensive use of FRP in structural components is, from an economic and technical viewpoint, only suitable in small-scale manufacturing. Another major development is the increased usage of aluminium [38-40] and magnesium [41]. A prominent example for full-aluminium car bodies are spaceframe structures. [38]

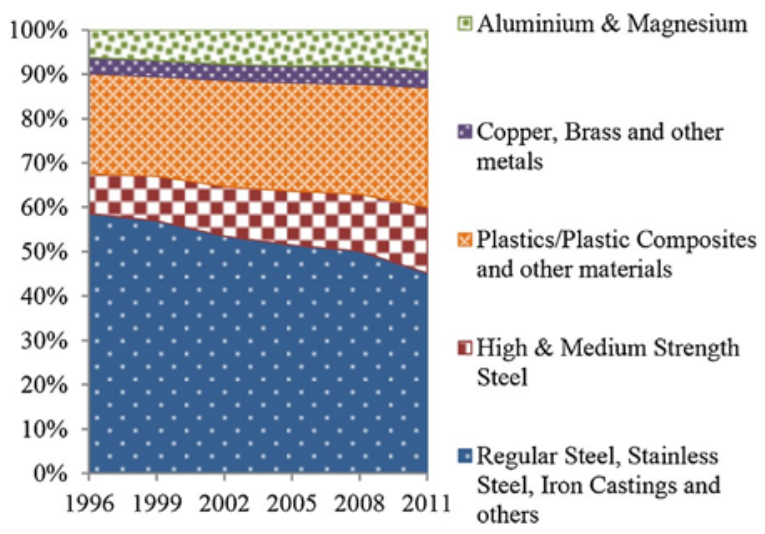

Fig.5.Increasing use of lightweightmaterials in vehicle design [33]; according to US Department of Energy 2013.
Magnesium has mainly been applied on a component level, such as in hoods and roof structures (Kulekci et al. provide an overview of applications [41]). The last decade has also shown a trend to introduce multi-material structures in car bodies. The underlying idea is to match mechanical properties to the specific loads through the application of a variety of materials [42]. Furthermore, lightweight structures can be enhanced by the realisation of functional integration through combining different materials on a component level. Multimaterial structures require new process technologies in order to enable an introduction into large-scale manufacturing routes, as demonstrated by Eckstein et al. [43].

\subsubsection{Aerospace}

From the very beginning, lightweight structures have been one of the most important drivers in the aerospace manufacturing. Composites have become critical materials to achieve lightweight objectives for the aerospace industry due to their specific stiffness-tostrength ratio and their high potential for multi-functionality. This includes defined anisotropic behaviour, the possibility to integrate sensors or actuators, high structural damping, and superior fatigue performance. As a result, the use of composites in the aerospace industry has evolved from around $15 \%$ to more than $50 \%$ of the total structural mass in the last 25 years [44-46]. The use of composites requires new approaches for the design and service of structural components due to industry specific and stringent safety regulation and the associated durability, maintenance and repair. Therefore, the challenge with lightweight aerospace structures is to find the optimum compromise through a multidisciplinary approach with life cycle thinking, starting frommaterial selection, design, use and maintenance, and end-of-life. While the common focus in industry used to be on cradle-to-gate, with economics being the main driver [44,45], studies by Timmiset al. as well as Bachmann et al. take the environmental life cycle perspective into account, including the use stage and end-of-life of lightweight aircrafts $[46,47]$.

\subsubsection{Machine tools}

The application of lightweight structures in machine tools serves as a measure towards enhancing the mechanical performance of a machine or enabling an increased energy efficiency during its operation. Yoon et al. introduce a hierarchical approach to energy saving strategies. The introduction of lightweight structures would be subsumed as a hardware-based optimisation within the field of energy efficiency [48]. Successful examples show the joint application of different weight reduction strategies, combining the application of new materials with the adaption of machine geometries as discussed for instance in Refs. [49,50].

An overview of state-of-the-art materials in machine tools is provided in Refs. [26-28]. Research on lightweight machine tools through the use of bionics is discussed in Ref. [51]. The introduction of composites is the focus of research in several examples. This is especially relevant for structures carrying high mechanical loads. Fig. 6

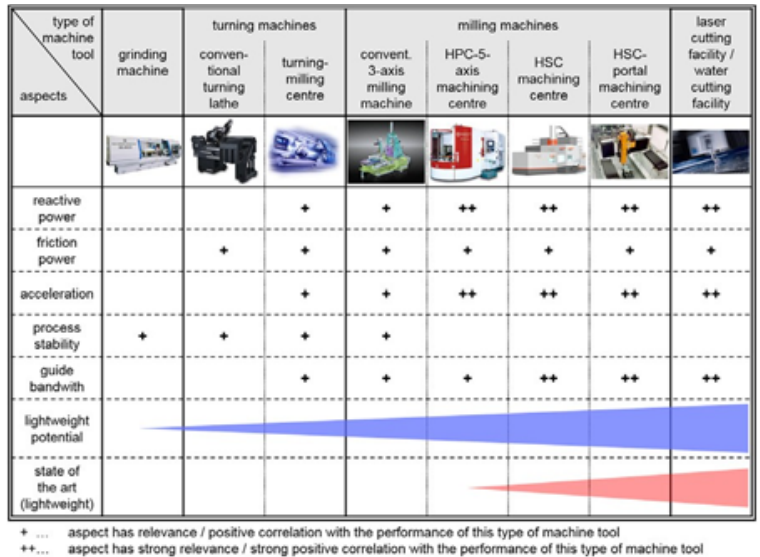

Fig. 6. Lightweight design potentials for various machine tools [27]. 
depicts potentials for weight reduction in various machine types. The relevance of lightweight design measures for different types of machine tools is dependent on aspects such as the field of application and the size of the machine. In the case of grinding machines, the benefit of weight reduction is limited, as the drive power is needed almost exclusively for the process realisation and not for the acceleration of feed axes. Turning and milling often only show average axial accelerations and require a certain level of stiffness when applied for high-precision applications. In contrast, HPC 5axis milling centres execute complex, super-imposed path motions (several axes engaged) and frequent acceleration and deceleration movements. Furthermore, electrical losses can be minimised due to lower mass inertia. In general, machines that show high acceleration levels, reactive or friction powers are identified as suitable candidates for weight reduction. When process stability and stiffness is the focus, lightweight structures could have a negative influence [27]. Neugebauer et al. stress the advantages of weight reduction with regard to spatial flexibility of production systems, for example by moving the production systemtowards a large product, instead of moving the product itself [52].

\subsection{Literature review}

Fig. 7 summarises the reviewed publications using a chord diagram. In total, 131 research papers and reports targeting the topic of LCE of lightweight structures have been identified. This excludes research that only focuses on the realisation of lightweight structures or contributions that put forward LCE ina generic manner. Building structures as applications were excluded from this review. The chord diagram shows relationships between reviewed publications, different lightweight levers and application areas. The numbers positioned around the circle represent the publications according to the reference list of this paper. The different levers and application fields are placed around the circle as well. In addition, addressed environmental impact
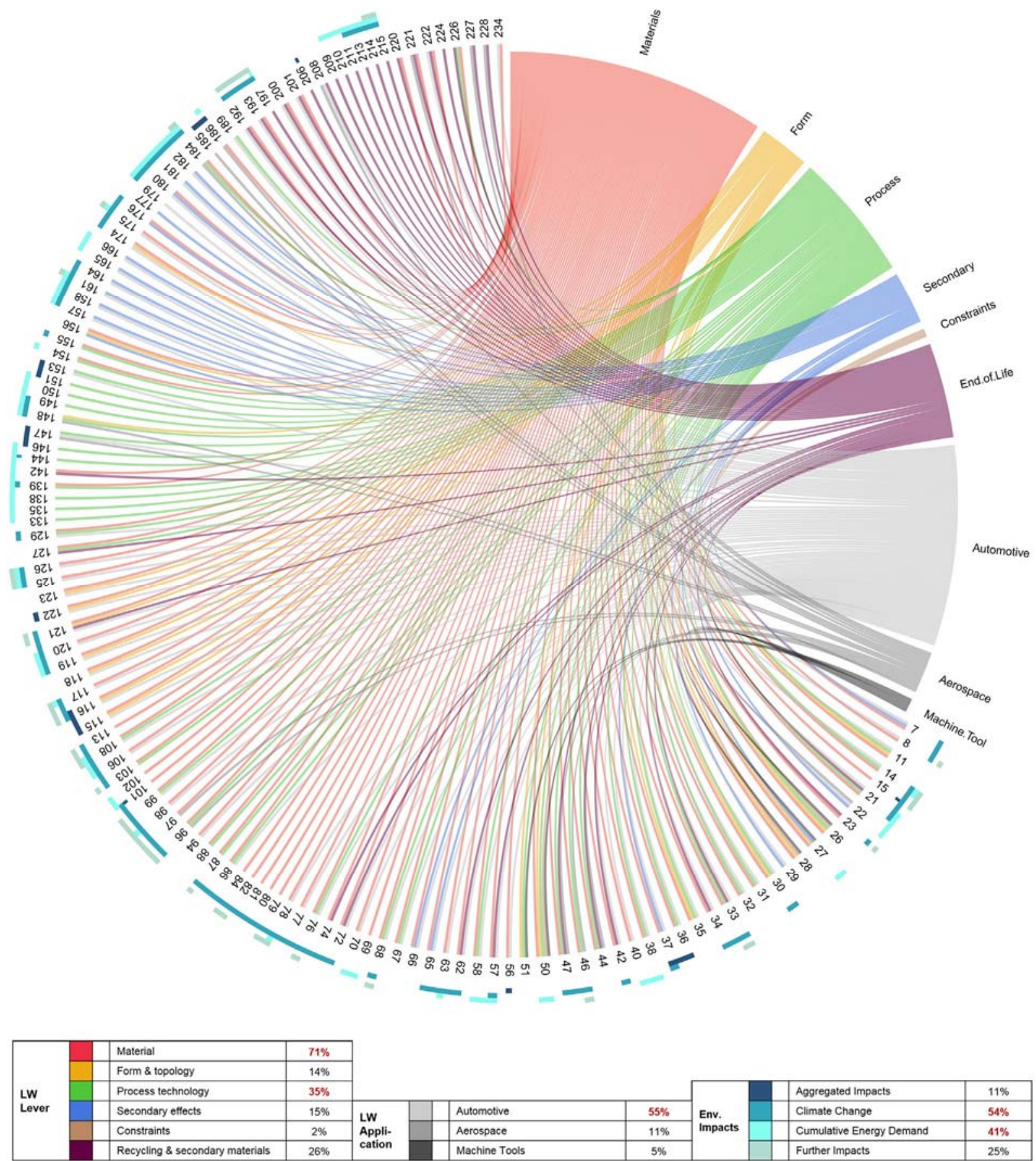

Fig. 7. Categorisation of the reviewed literature addressing LCE of lightweight structures (131 papers and reports in total, listed according to the numbering of the reference list); depiction of addressed lightweight levers, application domains and analysed impact categories. 
categories are marked through a colour coding on the outer ring. Each publication can target one or more lightweight levers. Applications could be generic (no link shown) or specific (links shown in grey colour).

Leveraging weight reduction by selecting a different, lighter material is a dominating aspect within the reviewed publications. This reflects the fact that the type of material selected has a strong effect on the overall product weight and on the environment. The review highlights a large number of publications targeting new manufacturing processes, their contribution to manufacture lightweight structures as well as energy and resource efficiency in manufacturing. Another major stream of literature discusses the development of end-of-life treatment processes for lightweight structures as well as research on the application of secondary materials. Research explicitly targeting the interplay between LCE and lightweight structures through constraints is scarce.

The majority of publications employs automotive cases when regarding lightweight structures. This reflects the multitude of influences lightweight structures could show on the environmental performance of vehicles regarding foreground and background systems. While many publications aim at achieving a holistic view on environmental impacts of lightweight structures, most quantitative studies are limited to impacts on climate change or the energy demand of the studied system. Less than half of the quantitative studies analyse further impact categories.

\section{Extraction and production of lightweight materials}

The use of different, lighter materials and/or the combination of these materials for lightweight applications strongly correlates with breakthrough product and process innovations. Ashby presents the evolution of engineering materials over time by assessing the number of teaching hours dedicated to those materials [53]. In the 1940s, light alloys, such as aluminium, magnesium or titanium emerged. The importance of metals, especially steel alloys, peaked in the 1960s. Subsequently, ceramics, polymers and composites, such as FRPs became available for engineering applications and steadily gained importance.

To investigate options to reduce the environmental impact related with the use of (lightweight) materials from a top-down perspective, Allwood et al. [54] modified the Kaya identity (an extended variant of IPAT) to describe total energy and process emissions (C) associated with the material production (see Eq. (1)). C is calculated as the product of demand for goods (D) containing material, the average mass of material per product $\left(M_{P} / D\right)$, the yield ratio of material supplied to material eventually occurring in the product $\left(M_{S} / M_{P}\right)$, and the average emissions per unit of material $\left(C / M_{S}\right)$. By expanding the Kaya identity, the demand $D$ is set to the sum of a new demand $N$ and a replacement demand $(S / L)$, where $S$ is the stock of existing goods and $L$ is their average lifespan. The additional factors in the equation account for the different emission factors when the material is sourced from primary ore $\left(C_{O} / M_{O}\right)$, recycling $\left(C_{R} / M_{R}\right)$, and re-use $\left(C_{U} / M_{U}\right)$ with $M_{S}=M_{O}+M_{R}$ $+M_{U}$, and the fractions $f_{O}+f_{R}+f_{U}=1$.

$C=\left(N+\frac{S}{L}\right) \cdot \frac{M_{P}}{D} \cdot \frac{M_{S}}{M_{P}} \cdot\left(f_{O} \frac{C_{O}}{M_{O}}+f_{R} \frac{C_{R}}{M_{R}}+f_{U} \frac{C_{U}}{M_{U}}\right)$

With respect to reducing energy and process emissions of materials, the interpretation of Eq. (1) leads to five main conclusions: (i) products should be designed using less material $\left(M_{P} / D\right)$, (ii) post production waste should be minimized $\left(\mathrm{M}_{\mathrm{S}} / \mathrm{M}_{\mathrm{P}}\right)$;

(iii) materials should be selected taking their life cycle environmental footprint into account (C/M), (iv) recycling and reuse of components should be preferred and supported $\left(f_{R}, f_{U}\right)$; and, $(v)$ the products' lifetime $(\mathrm{L})$ should be considered when analysing the overall impact of lightweight structures, taking into account that different structural designs and materials lead to different constraints with regard to maintenance and repair [54].
Processing technologies for extracting and providing lightweight raw materials are undergoing a development towards higher process efficiencies over time, generally following an S-curve. One measure of higher efficiency is the reduction of process energy demands as well as the minimisation of harmful environmental impacts. Other directions are the reduction of yield losses and the reduction of impurities of materials streams. Gutowski et al. discuss the increase of process efficiencies within the steel and aluminium industries [55]. Both industries have shown a decrease of the required amount of energy for raw materials extraction and production by a factor of five within the last 200 years, approaching their thermodynamic limit. As a result, further dramatic improvements are less likely to be achieved [55]. This situation changes when looking at relatively new engineering materials. For instance, the manufacturing of poly-acrylnitrile (PAN)-based carbon fibres requires ten to fifteen times the amount of energy compared to the same mass of steel. This increased embodied energy results in higher massspecific greenhouse gas emissions from that stage $[56,57,58]$. However, the required amount of material with respect to functional requirements needs to be taken into account. At the same time, current carbon fibre manufacturing mainly targets high performance applications. Adapting fibre manufacturing to the needs of a mass produced product could enable significant efficiency gains [59].

Another factor influencing the environmental impact of material selection is the sourcing of those materials. For instance, materials can originate from different geographic regions with different environmental impacts. Later processing steps may also be globally distributed, in some cases to leverage low cost energy provision for energy-intensive processing steps. Production capacity may also be set up in emerging markets to meet growing local demand. The global trade chain of aluminium has been mapped by Liu and Müller in a material flow analysis [60]. Fig. 8 shows geographical sources and sinks of aluminium material flows at different stages of the value chain, from raw materials extraction to scrap material. On this basis, in a separate publication, they show that greenhouse gas emissions from aluminium vary by a factor of over 3 per $\mathrm{kg}$ of primary material, depending on the geographic region [61]. As engineering materials are often purchased as commodities on a global market, the environmental impact of a tonne of raw material is usually considered as a global average. This includes different process technologies as well as energy sources applied to produce those materials. However, the application of global averages can mask opportunities to significantly reduce environmental impacts by sourcing materials from regions with favourable production conditions. Another strategy would be to drive a technology change in the respective, mostly

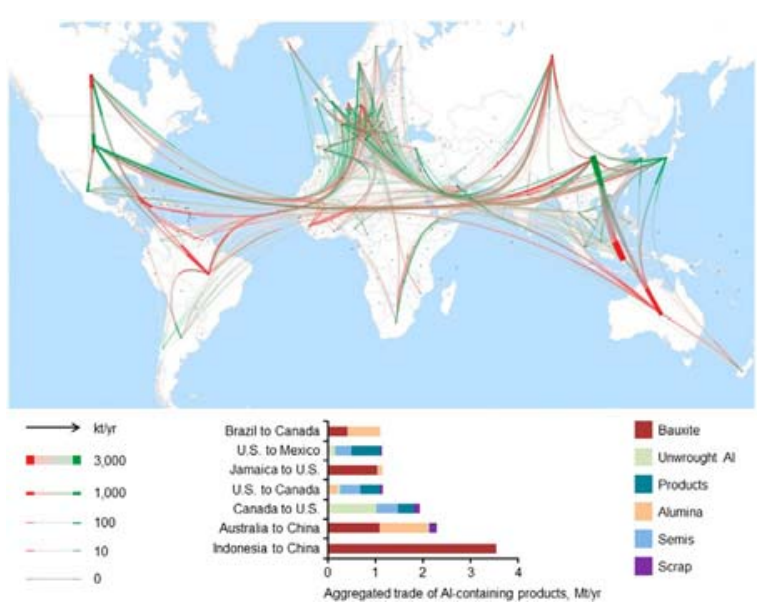

Fig. 8. The global aggregated trade flows of aluminium in bauxite, alumina, unwrought aluminium, semis, finished products, and scrap for the year 2008. The thickness of a flow (origins in red and destinations in green) is proportional to itsphysical trade value [60]. 
Selected embodied carbon footprint, lightweight performance indicators and weight reduction potentials for lightweight materials in automotive applications.

\begin{tabular}{|c|c|c|c|c|c|}
\hline \multirow[t]{2}{*}{ Lightweight material } & \multirow{2}{*}{$\begin{array}{l}\text { Carbon footprint raw materials } \\
\left.\text { extraction }\left[\mathrm{kg} \mathrm{CO} \mathrm{CO}_{2} \mathrm{eq} / \mathrm{kg}\right)\right]\end{array}$} & \multicolumn{3}{|c|}{ Lightweight performance indicators [1] } & \multirow{2}{*}{$\begin{array}{l}\text { Final component weight } \\
\text { (automotive case) }\end{array}$} \\
\hline & & $\begin{array}{l}\text { Static strength } \\
\text { (tensile) } \\
\frac{K_{m ; i}}{g_{i} r_{i}}=\frac{K_{m ; \text { Steel }}}{g_{\text {Steel }} r_{\text {Steel }}}\end{array}$ & $\begin{array}{l}\text { Static longitudinal } \\
\text { stiffness (tensile) } \\
\frac{E_{j}}{g_{i} r_{i}}=\frac{E_{\text {Steel }}}{g_{\text {Steel }} r_{\text {Steel }}}\end{array}$ & $\begin{array}{l}\text { Shear stiffness } \\
\text { (torsional) } \\
\frac{G_{i}}{g_{i} r_{i}}=\frac{G_{\text {Steel }}}{g_{\text {Steel }} r_{\text {Steel }}}\end{array}$ & \\
\hline $\begin{array}{l}\text { Steel (low-alloyed) } \\
\text { (Advanced) High-strength steel }\end{array}$ & $\begin{array}{l}2.2 \text { (blast furnace) [62] } \\
2.8 \text { (blast furnace) }[62]\end{array}$ & 1.00 (reference) & & & $\begin{array}{l}1.00 \text { (reference) } \\
0.9 \text { (HSS) }[63,64] \\
0.7 \text { (HSS) [65] } \\
0.75-0.85 \text { (AHSS) }[63,66,67]\end{array}$ \\
\hline Aluminium & 9.7-18.3 (primary) $[61,62]$ & 1.67 & 0.97 & 0.94 & $0.5-0.6[63-67]$ \\
\hline Magnesium & 25.8 (pidgeon) [68] & 1.93 & 0.97 & 1.00 & $0.35-0.5[63-67]$ \\
\hline $\begin{array}{l}\text { GFRP (glass fibre reinforced } \\
\text { polymers) }\end{array}$ & $2.4(30 \%$ GF) [57] & 12.75 & 0.65 & 0.30 & $\begin{array}{l}0.65-0.75 \text { (non-specified) } \\
{[66,67]} \\
\text { Up to } 0.4 \text { (unidirectional) [63] }\end{array}$ \\
\hline $\begin{array}{l}\text { CFRP (carbon fibre reinforced } \\
\text { polymers; PAN-based) }\end{array}$ & 14.6 (29 vol\% CF) [69] & 5.75 & 3.00 & 1.05 & $\begin{array}{l}0.4-0.5 \text { (isotropic) } \\
{[63,64,66,67]} \\
0.25-0.3 \text { (unidirectional) } \\
{[64,70]}\end{array}$ \\
\hline
\end{tabular}

Further reviews on the carbon footprint of fibre and matrix materials are provided in Refs. [57,58].

developing, regions by reducing the environmental impacts for energy provision and process technologies through adequate measures. Climate change is the impact category considered in most of the reviewed studies. Table 1 compares greenhouse gas emissions on a mass basis for common engineering materials. Low-alloyed steels show the lowest greenhouse gas emissions per $\mathrm{kg}$ of material use in comparison to high strength steels, aluminium, magnesium and FRP.

Table 1 also provides comparative performance information regarding various measures of mechanical performance (strength, longitudinal- and torsional stiffness). A baseline is represented by an aluminium structure. Optimising static tensile strength behaviour, CFRP structures could be lighter by a factor of 3.45 compared to aluminium structures. Such simplified indicators enable an early estimation of suitable lightweight materials and their environmental impacts [1].

Several studies have analysed achievable weight reductions for material substitution scenarios in automotive applications (see Table 1). In general, median weight reductions of about $10-30 \%$ are enabled through high-strength or advanced high-strength steels. Aluminium, magnesium, composites and plastics show even higher potentials for weight reduction. Those numbers are both relevant to determine the environmental impacts in the stage of raw materials provision and end-of-life, but are as well crucial towards quantifying the potential decrease of environmental impacts during the use stage.

\subsection{Steel, magnesium and aluminium in lightweight structures}

Metals have been the primary engineering materials used by humanity for the past two centuries [53]. Steel, aluminium, magnesium and titanium are the metal types most widely applied in the realisation of lightweight structures. However, unlike steel, aluminium and magnesium, the application of titanium is underrepresented in the literature considering aspects of life cycle engineering.

Alloying as well as different manufacturing routes allow the realisation of a wide range of mechanical properties with respect to the intended application [71]. Modaresi et al. quantify global carbon benefits when introducing aluminium and steel light-weight structures in vehicles on a large scale. They show that material substitution could cumulatively save between 9 and 18 gigatonnes of $\mathrm{CO}_{2}$-eq globally by 2050 . However, this only applies if the complete technically feasible potential is realised, all secondary mass savings are leveraged, and all countervailing effects (e.g. increasing weight due to safety and comfort) are avoided [72]. Nuss and Eckelman contribute further with a comprehensive method to assess 63 different metals. Environmental hotspots are shown to typically occur in the purification and refinement stage. While emissions per kilogramme for broadly used engineering materials are at the lower end of the scale, the market quantities make iron and aluminium the total largest contributors of greenhouse gas emissions [73].

Two main steel manufacturing routes can be distinguished. The blast furnace route $(70 \%$ of world steel production) typically operates with a significant share of scrap material (up to $35 \%$ ). The electric arc furnace route allows a major share of scrap material content (up to $100 \%$ ). Both routes could realise all relevant industry products - thus their share of the regional market share is strongly related to the available flows of primary and secondary materials [74]. The World Steel Association, which represents approximately $85 \%$ of the world's steel production, states that it aims to provide up-to-date and consistent life cycle inventory data. So far, data for 16 steel products are available [75].

In steel manufacturing, alloying elements such as chromium, nickel, manganese, silicon, and molybdenum influence properties such as strength, corrosion resistance and formability as well as trade-offs between these properties [71]. Innovations in manufacturing process routes and alloying have led to a number of high performance steels such as high strength steel (HSS) and advanced high strength steel (AHSS), which have enabled a decrease of product weight of products by reducing the sheet metal thickness $[30,76]$. Kelly et al. calculated GHG emission reductions for HSS and AHSS for different vehicle body and chassis structures, showing the highest reduction of around $20 \%$ for AHSS applied to door frames [77]. Hardwick and Outteridge performed a life cycle assessment on AHSS designs carrying molybdenum as an alloy in comparison to conventional steel designs. For this specific case, additional environmental impacts through the increased share of molybdenum were compensated through advantages in metal processing and the increase in mechanical performance [78].

\subsubsection{Aluminium}

With respect to the desired manufacturing process route, a distinction is made between wrought and cast alloys for aluminium. While wrought alloys enable higher strengths, cast alloys allow the manufacturing of the near final shape of the product. Major alloying elements include copper, silicon, magnesium, zinc and manganese. Since wrought alloys are mainly manufactured from virgin materials or are part of a closed loop recycling from production scrap, recycled aluminium alloys from end-of-life products can typically only be used in casting [71].

The main hotspot in primary aluminium production is electricity provision, contributing between $25 \%$ and $80 \%$ of overall environmental impacts. In 2010, China was the largest producer of primary aluminium, followed by Europe and North America. Whilethe global share of hydro power in electricity sources for aluminium was about $41 \%$, this number has been significantly 
smaller for China, where coal has the largest share in power generation [79]. Greenhouse gas emissions per $\mathrm{kg}$ of aluminium produced can vary with a factor bigger than three, depending on whether it was produced in Asia or Latin America, largely driven by the availability and utilisation of hydropower [80].

Although LCA data is usually averaged across a country or region, it is best to use emission factors associated with the relevant energy sources (coal, gas, nuclear, hydro, wind, solar) used to generate electricity to drive aluminium production. In their study, Colett et al. investigated the difference between using an average versus a refined emission factor in a specific situation and calculated a specific factor of around $20 \mathrm{~kg} \mathrm{CO}$-eq per $\mathrm{kg}$ compared with $11 \mathrm{~kg}$ $\mathrm{CO}_{2}$-eq per $\mathrm{kg}$ in studies often quoting data from the GREET Model [81]. This highlights one challenge for LCE: Using predefined data and models as 'black-boxes' runs the risk of not asking questions about data quality and model validation.

\subsubsection{Magnesium}

In the case of magnesium, four main process routes are distinguished. One is the electrolysis route. Three alternative thermal process routes are established, with the pidgeon process being the most prevalent supply route on the market [82]. The pidgeon process is one of the oldest and is widely used among producers in China [83]. In 2011, Chinese production represented more than $80 \%$ of the global supply $[68,84]$ following a steady increase [85]. Magnesium processing by the electrolysis route typically shows lower environmental impacts for all relevant impact categories compared to pidgeon processing. This results from a higher process efficiency and lower impacts from the applied energy mix for the electrolysis route [82]. The past few years have shown a transition towards gas energy for Chinese magnesium production $[68,85]$. A major effect on climate change for alloying of magnesium can be observed by the application of cover gases to prevent oxidation. The application of $\mathrm{SF}_{6}$ (global warming potential of $23,900 \mathrm{~kg} \mathrm{CO}$-eq per $\mathrm{kg}$ gas according to IPCC) has fallen back in favour of HFC-134a (global warming potential of 1430-3300 kg $\mathrm{CO}_{2}$-eq per $\mathrm{kg}$ gas) or $\mathrm{SO}_{2}$ (no GWP impact, but impact on acidification potential) $[68,82]$. Tharumarajah and Koltun studied the life cycle benefits to vehicles when introducing magnesium engine blocks. Magnesium shows lower environmental impacts in comparison to iron, aluminium and compacted graphite iron references. However, this advantage diminishes when applying pidgeon magnesium from China [86].

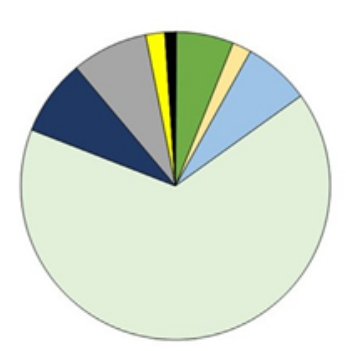

$\square$ Normal release agent $(<1 \%)$ a Gelcoat $(6 \%)$

$\square$ Gelcoat application (brushed) $(2 \%)$ aChopped strand mat (CSM) $(7 \%)$ 口Polyester $(66 \%)$

-Open mixing polyester $(8 \%)$

arushing polyester $(8 \%)$

$\square$ Consolidate by roller $(2 \%)$

$\square$ Cure at room temperature $(0 \%)$

पTrim by electric hand $(<1 \%)$

- Acetone mould cleaning ( $1 \%$ )

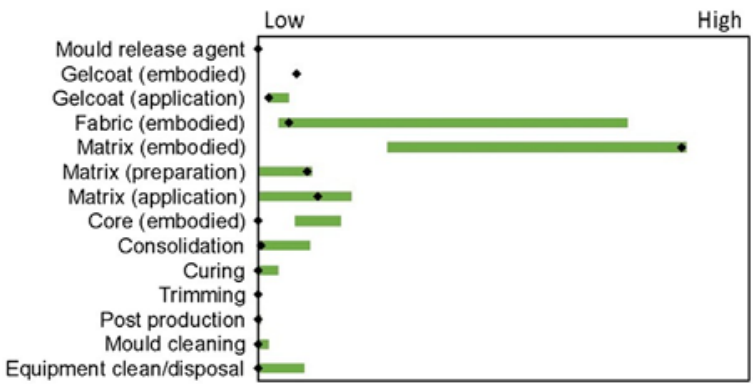
production and manufacturing and relative impact of each stage for hand lay-up of chopped glass fibre reinforced polyester [87].

\subsection{Fibre-reinforced polymer composites (FRPS)}

FRPs combine properties of the constituting fibre and matrix components in such way that very high stiffness-to-weight or strengthto-weight ratios can be achieved. Anderson et al. provide a structured overview of key environmental- and social impacts of composite production and manufacturing processes, which differ greatly amongst the available FRPs [87] (Fig. 9). Nevertheless, for most composites the environmental impact of the manufacturing stage is an order of magnitude lower than the production impact of the constituting matrix and fibre materials.

\subsubsection{Matrix materials}

Thermoset resins, such as epoxy or polyester, are still the dominant matrix materials. Nevertheless, thermoplastics such as polypropylene are considered alternative matrix materials due to shorter cycle times in manufacturing. Moreover, they provide the benefit of higher recyclability and often exhibit better impact properties than their thermoset counterparts. However, thermo-plastic matrix materials have a significantly higher viscosity during processing, thus necessitating more expensive manufacturing equipment. In addition, the interfacial fibre/matrix bonds tend to be weaker [88]. Lyu and Choi review the state of the art of polymers applied in vehicles. Key properties that were considered include chemical resistance, temperature stability or aging behaviour [89]. Recently, bio-based matrix materials, such as polylactic acid (PLA), modified starch, polyhydroxyalkanoates (PHAs), and epoxidized linseed oil (ELO), are being considered in engineering applications $[57,90]$. Some of these can be biodegraded [91], which may or may not be beneficial, depending on the application of the composite. Challenges of bio-based matrix materials include higher production cost and potential competition with the food supply chain in sourcing feedstock. Second generation biobased polymers sourced from side streams that do not compete with the feedstock, such as wheat gluten, are currently under development [92]. A review on greenhouse gas impacts of different matrix materials is provided by Duflou et al. [57].

\subsubsection{Fibre materials and fibre-reinforced composites}

Glass-, carbon, and aramid fibres are most commonly used due to their high strength and stiffness. Production temperatures, which may reach up to around $1550^{\circ} \mathrm{C}$ for glass fibres, $1000-1400^{\circ} \mathrm{C}$ for high-stiffness carbon fibres, and $1800-2000^{\circ} \mathrm{C}$ for high-strength carbon fibres, however, lead to high energy intensities of fibre production $[57,69]$. Carbon fibres have mainly been applied in aviation, but are now finding additional use in road vehicles or sports equipment. Precursor fabrication largely determines the material properties and final quality of the carbon fibre. Moreover, it represents a major cost factor during production and has therefore been thoroughly investigated in recent years [93]. Mainka et al. focus on the replacement of the conventional, fossil-based polyacrylnitrile (PAN) precursor with lignin, thus enabling reduction of energy demands and cost [94]. The stabilisation and carbonisation steps aim at maximising the carbon yield from the fibre. To achieve the required carbon content in the fibre, various chemical compounds (including $\mathrm{HCN}, \mathrm{NH}_{3}$ and $\mathrm{CH}_{4}$ ) are removed in a carefully controlled thermal atmosphere $[95,96]$.

Despite its energy intensive processing, carbon-fibre reinforced structures tend to show similar or lower impacts in manufacturingwhen compared to aluminium structures, when taking into account the weight reductions that can be achieved. This is explored in studies by Achternbosch et al. as well as Khalil et al. [96,97]. By providing case studies on automotive components, Witik et al. as well as Koffler point out potential environmental benefits of glass fibre reinforced composites, for the case of replacing a steel design while retaining mechanical functionality $[98,99]$. Duflou et al. provide a comparison of a steel body-in-white to an equivalent CFRP design. In the given case, a weight reduction leads to lower fuel consumption. By calculating different scenarios, 
the environmental break-even point can be determined [57]. A graphical presentation supports the system understanding and helps to derive conclusions. A typical visualisation of the environmental performance of lightweight structures is the representation in breakeven charts. These charts typically allow an easy comparison of two alternative designs with different life cycle environmental impacts (see Fig. 10)

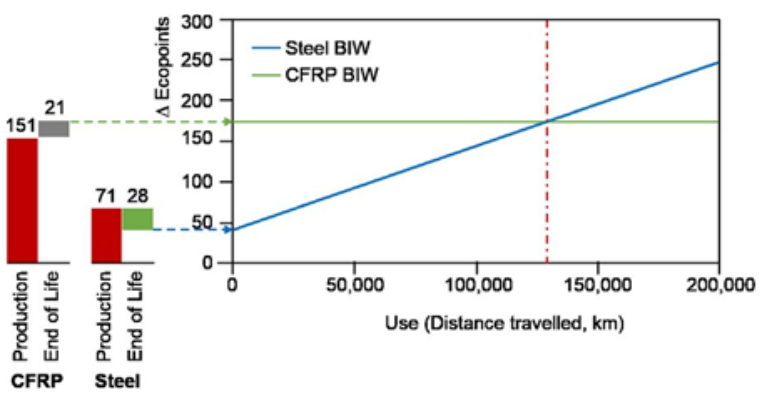

Fig. 10. Total life cycle impact of a carbon fibre-reinforced polymer (CFRP) body-in-white (BIW) compared to a conventional steel BIW [57].

The importance of natural fibre composites is increasing, with an expected global market of nearly USD 11 billion by 2024 driven by the automotive industry's share of about one third of the market [100]. Natural fibre materials that are increasingly used in technical applications include flax (64\% of the market), jute (11\%), hemp (10\%), and sisal $(7 \%)$, with these market shares showing good correlation with their mechanical properties [101]. Meanwhile, the use of recycled cotton fibres is increasing [102]. In addition to renewability, important drivers of natural fibre use are low cost and low density, with density values reaching as little as $1.5 \mathrm{~g} / \mathrm{cm}^{3}$ for some plant fibres as compared to around

$2.5 \mathrm{~g} / \mathrm{cm}^{3}$ for glass fibres [101]. Natural fibres can compete with glass fibres especially on their stiffness-to-weight ratio, and less so on their strength-to-weight ratio [103]. Moreover, natural fibre-reinforced composites can exhibit damping properties superior to that of glass fibres [104]. Drawbacks of natural fibres include their natural variability of mechanical properties, processing temperature limitations, worse interfacial fibre/matrix bonds and moisture absorption [102,105]. Alkal based treatments and the steam-based Duralin process can be used to improve their performance in this respect, yet both come with a nonnegligible increase in environmental impact [102].

A generalized comparison of the performance of natural fibre composites to glass fibre composites remains cumbersome due to open research questions regarding service life and adequate replacement ratios between flax-FRP and glass-FRP [103]. Especially when this leads to a premature end-of-life for an entire system, the environmental impact increases drastically. This adds to environmental concerns for NFRPs regarding emissions of nitrogen and phosphorus to waterways over large areas of arable land, which are caused by the farming of natural fibres. Boland et al. examine the changes in environmental impact when replacing glass fibres with kenaf or natural cellulose in automotive applications [106]. While the manufacturing energy demands of all alternatives are in a similar range, the natural fibre composites are lighter and thus show benefits over the life cycle. Besides greenhouse gas emissions, the importance of discussing the biogenic carbon storage of natural fibres is highlighted [106].

Self-reinforcing composites (SRCs) are a novel category of composites that consist of both fibre and matrix of the same polymer $[88,107]$. In particular, SRCs that comprise a polypropylene matrix reinforced with highly oriented propylene fibres are commercially available. SRCs do not only exhibit increased stiffness compared to the matrix material, but also improved strength and impact performance - even outperforming carbon FRPs and glass FRPs with respect to the latter criterion. This can be attributed to the obvious chemical compatibility between fibre and matrix [88]. Delogu et al. present a comprehensive assessment on hollow glass microspheres as reinforcement to replace talc fillers. Using the example of an automotive dashboard, the trade-off is discussed between the impact categories that are dominated by influences from the manufacturingand the use stage [108].

\subsection{Life cycle oriented engineering tools for material selection}

Ashby introduces a generic and widely applied approach to support material selection and to facilitate the realisation of lightweight structures considering mechanical, economic and environmental properties $[109,110]$. In this approach, constraints serve as a measure to exclude certain materials. Target functions enable the selection of an optimal material that fulfils all set constraints. As proposed by Jahan et al., material selection should encompass material properties, a holistic view on economic and environmental considerations, the processing of materials, effects from producing large quantities as well as future raw materials accessibility [111]. Table 2provides an overview of 16 identified material selection methods in the context of LCE of lightweight structures. In addition, a narrowed-down evaluation with respect to the scope of interest is provided.

One focus in developing methods has been set on specific application fields, e.g. addressing the complexity in evaluating vehicle structures. Another focus lies on methods enabling a selection of specific materials or material families. An additional perspective is the interdisciplinary consideration of form and topology when introducing structures that apply new materials. For instance, the availability and geometry of installation space limit certain options from a design perspective [112]. In addition to such categorisations, further technical requirements may be included, such as behaviour under thermal stress. The simultaneous assessment of environmental impacts and cost enables an evaluation in terms of eco-efficient material selection. A large number of methods targets automotive applications. A transfer to other applications might be possible, but is not provided by the analysed literature. The focused materials are distributed equally across the literature, but only three publications contained a comparative study of metals, FRPs and hybrid materials. Most methods did consider form and topology. However, four studies

Table 2

Classification of methods supporting a life cycle oriented material selection.

\begin{tabular}{|c|c|c|c|c|}
\hline \multirow{3}{*}{$\begin{array}{l}\text { Application } \\
\text { Addressed materials }\end{array}$} & Generic $[113,114]$ & \multicolumn{3}{|l|}{ Automotive [63,115-126] } \\
\hline & FRPs & Metals & Hybrid & All \\
\hline & {$[113,114,116,125,126]$} & {$[63,119-121,124,125]$} & {$[63,115]$} & {$[117-119,123]$} \\
\hline Form/topology & $\begin{array}{l}\text { Generic } \\
{[113,114,124,126]}\end{array}$ & $\begin{array}{l}\text { Optimisation } \\
{[115,116,118,119,121-123]}\end{array}$ & $\begin{array}{l}\text { Consideration of installation space } \\
{[115,116,118,119,121-124]}\end{array}$ & $\begin{array}{l}\text { No focus } \\
{[63,125,126]}\end{array}$ \\
\hline Addressed life cycle stages & $\begin{array}{l}\text { Raw materials } \\
{[63,111-116,119,120,123-126]}\end{array}$ & $\begin{array}{l}\text { Manufacturing } \\
{[63,111-114,116,119,120,123-126]}\end{array}$ & $\begin{array}{l}\text { Use } \\
{[63,115,116,118-120,122,125,126]}\end{array}$ & $\begin{array}{l}\text { End-of-life } \\
{[63,113,115,118-123,125,126]}\end{array}$ \\
\hline Impact categories & $\begin{array}{l}\text { Aggregated } \\
{[111,114,116,119]}\end{array}$ & $\begin{array}{l}\text { GWP } \\
{[63,112,115,119,120,125,126]}\end{array}$ & $\begin{array}{l}\text { CED } \\
{[63,112,114,125,126]}\end{array}$ & $\begin{array}{l}\text { Further impacts } \\
{[113,121,126]}\end{array}$ \\
\hline Assessment of cost & $\begin{array}{l}\text { Yes } \\
{[114,115,117,118,120,122,123,126]}\end{array}$ & & & \\
\hline
\end{tabular}


relied on generic approaches that might reach their limits in complex applications. Out of the 16 methods studied, only three considered impact categories other than GWP, the cumulative energy demand or aggregated approaches.

\section{Manufacturing of lightweight structures}

The introduction of lightweight structures triggers the improvement of existing and development of new manufacturing processes. In terms of LCE, those production technologies need to comply with economic and quality targets as well as environmental requirements, as discussed in the following sections.

\subsection{Developments in metal- and FRP process chains for manufacturing of lightweight structures}

The manufacturing of lightweight structures needs to meet future demands in the automotive-, aerospace- and other industries. A key challenge in large volume production of lightweight composites and hybrid structures lies in the reduction of cycle times [127]. Process routes for structural components include well-established production steps, e.g. deep drawing, stamping or die-casting. Research efforts focus on improving and recombining existing routes and developing newprocesses.

An evolutionary development in metal stamping is the application of tailored blanks, which feature local variations of sheet thickness and thus result in increased material efficiency [32,128]. Ingarao et al. stress the importance of temperature effects when processing lightweight metals. Higher temperatures improve formability and enable a reduction of forces required for forming. In the case of high strength and ultra-high strength steels, force limits may be reached and result in the need for high power machinery due to greater dimensional deviations when forming such steels [129]. One example is the hotstamping of steels [130] in modern vehicle manufacturing. Raugei et al. performed a study to assess the environmental impacts of a novel sheet metal forming process (solution heat treatment, forming and in-die quenching (HFQ)) [131]. HFQ allows the forming of large sheet metal parts without the need for extraneous rivets or other bonding techniques. In comparison to a conventional scenario assembling smaller parts with a total of 360 steel rivets, it could be observed that the additional energy required for the HFQ process is more than balanced by the ensuing benefits in terms of enhanced end-of-life recyclability [131].

Combining conventional techniques enables the production of hybrid structures. Thermoforming of FRP sheets, for instance, shows similarities to hot stamping [132]. A hybrid process of sheet metal forming and injection moulding enables energy demand reduction by $20 \%$ compared to the reference process chain [133]. A further example of realising lightweight structures from metals and plastics is hydroforming of metals that can be applied to sheet and tubular structures and might be combined with injection moulding [134]. At a lower technology readiness level (TRL), incremental sheet forming is under development in the processing of lightweight alloys. According to a study by Ingarao et al., energy efficiency can be and material efficiency might be improved using this process [135]. Other approaches include hot temperature treatment [136].

Depending on the geometry and material of the final product, various production technologies are involved in making FRPs. A main influencing factor on the process is the choice of the matrix material. FRPs with a thermoplastic matrix are processed at higher temperatures than thermoset-based FRPs, but show better processing properties [127]. Furthermore, thermoplastic matrix composites show advantages in recycling of production scrap [137]. Filament winding processes are primarily used to produce rotationally symmetrical composite parts. Pultrusion is applied to produce open shape and hollow continuous profiles [127]. Tempering the shaping die is the main driver of energy consumption. Therefore, optimising the heating system is expected to reduce the energy demand [138]. Resin transfer moulding is known for its flexibility regarding part geometries and process variations. Applying higher pressures can be used to speed up impregnation of the fabric under vacuum conditions [127]. Hohmann et al. studied carbon fibre reinforced plastic processing with resin transfer moulding and revealed influencing parameters on the energy demand of the process. They found part size and thickness to be the main drivers of energy consumption [139]. Injection moulding excels due to its applicability to series production, as opposed to other composite part production techniques. Furthermore, it provides an opportunity for using recycled fibres. Short fibres are used predominantly in the process, but long fibres can be employed as well [127]. Furthermore, hybrid components elicit the development of joining technologies, which potentially pose challenges to the recycling activities in the end-of-life stage of products [137].

Automating textile preforming processes is a necessary step towards the series production of composite parts, as it enables the tailoring of individual product properties to the load-path determined by external forces and product geometry [137,140,141], leading to lighter components. Textile processes also play a role in closing the material loop by processing recycled materials to short fibre preforms [127].

Another lever is the reduction of production waste, which accounts for the largest share of overall CFRP waste [142]. The large fraction of production scrap (25-30\%) obstructs the use of organosheets based on woven fabrics to manufacture FRP parts [143]. Leveraging benefits of unidirectional fibre-reinforced tapes as a substitute for organosheets, Kropka et al. developed a concept for a high-speed tape laying machine, which shows promising results regarding cycle time and scrap rate [143]. Brecher et al. improved the cost- and eco-efficiency of a high-speed tape placement operation for flat plates. However, in order to fulfil quality requirements, tape laying speed should be varied in accordance with subsequent process steps [144].

\subsection{Additive manufacturing}

The topological optimisation of lightweight components might result in part geometries such as lattice structures that cannot be manufactured by subtractive processes. Additive manufacturing (AM) can be one way to exploit the weight reduction potential of such structures. While resource efficiency could increase through the manufacturing of near-net shape products, additive manufacturing might be more energy intensive than conventional machining processes [145]. According to a study by Kellens et al., additive manufacturing shows environmental benefits only if the manufactured products offset the higher environmental burden by enabling additional functional improvements in the use stage. They conclude that the use of 3Dprinted lightweight parts is more likely to be beneficial in aerospace and railway applications than in the automotive industry when considering the full product life cycle $[146,147]$. Huang et al. estimate the environmental effects of AM on the aerospace sector while including engineering criteria, inventory data, the fleet stock, and fuel use models. In an ideal scenario, fleet-wide life cycle primary energy savings might reach 70-173 million GJ/year by 2050. In addition, relevant stocks of aluminium, titanium and nickel alloys could be potentially saved [148]. With regard to further research demands, Kellens et al. conclude in another study that "[ . . . ] LCl data on resource consumption and direct or indirect process emissions are mostly not available, [ . . . ] AM feedstock production processes are not well documented [and] the higher environmental impact caused during the AM manufacturing stage should be compensated by functional improvements [ . . . ]."[146]. On a process level, LutterGünther et al., Gebbe et al. as well as Kellens et al. contribute to the quantification of resource efficiency of laser beam melting and selective laser sintering. [149-151] 


\subsection{Life cycle oriented engineering tools in manufacturing}

A major challenge in manufacturing lightweight structures is the adequate planning of process chains incorporating new process technologies and their integration into factory environments. Schönemann et al. introduce a multi-level simulation framework for manufacturing lightweight components. Various sub-models (for product, machine, process chain and technical building services) are connected and applied to predict performance indicators during manufacturing, depending on product characteristics [152]. Ribeiro et al., Fanghänel et al., as well as Lindner and Schmitt developed integrated analytical approaches for planning process chains with regard to economic, environmental and functional performance dimensions. Modelling on a process level enables the prediction of impacts of certain process chain [153-155]. Le Duigou et al. focus on a closed loop design methodology for metals instead, aiming at increasing the recycled aluminium content in the final part [121].

\section{Use stage and integration of background system(s)}

The impact of a lightweight structure on a product's use stage strongly depends on its purpose and use scenarios. Lightweight structures that are applied to a mobile product affect the required kinetic energy to move that product. Such effects are called primary effects. Indirect or secondary effects are those changes that result from an adapted design and dimensioning through the reduction of weight (lightweight lever D). While lightweight structures are a means to achieve such virtuous cycles, they often have come with higher environmental impacts in stages other than the use stage. Thus, lightweight structures need to be evaluated in a LCE context as suggested by Fig. 11.

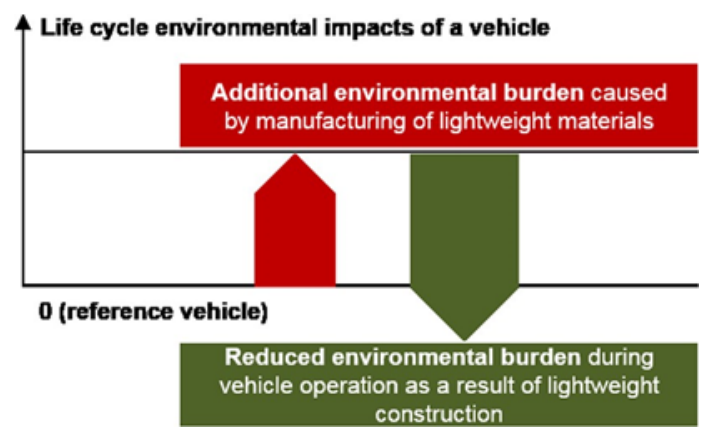

Fig. 11. Environmentally acceptable lightweight construction [156].

\subsection{Automotive}

In automotive structures, the energy demand of the use stage results from the work it takes to produce vehicle movement and to satisfy auxiliary demands, e.g. for air conditioning. The total work for vehicle movement is an integral of the traction force over a certain distance divided by the drivetrain efficiency. Drag force, force to overcome rolling resistance, elevation force and acceleration force sum up to the total driving force [157]. While the vehicle mass does not influence the drag force, all other forces depend on the vehicle mass. That includes acceleration forces, rolling forces, elevation force and mechanical losses in the drivetrain [158]. Kim et al. review 43 studies regarding main parameters influencing the life cycle energy and GHG benefits for lightweight vehicles [65]. This includes a review of average weight reductions as well as average driving distances. Weymar et al. provide a stochastic approach for determining average driving distances per vehicle class using Germany as an example [159].

In order to quantify the effects of lightweight structures on the use stage, they are typically compared to a reference structure. In that course, energy savings in the use stage are evaluated via so-called Fuel Reduction Values (FRV), and in the case of electrified drivetrains, Energy Reduction Values (ERV). These indicators single out the effect of a lightweight structure on the energy demand in the use stage. Hence, there is a direct link between environmental assessment and an engineering property, i.e. component weight. A typical scenario is the assessment of energy demands in standardised test procedures or driving cycles. In driving cycles, the elevation force is usually neglected $[157,158]$. Typical test procedures in the lab environment are the NEDC (New European Driving Cycle), the US Federal Test Procedure (FTP), applied by the EPA, or the recently introduced Worldwide Harmonized Test Procedure (WLTP). In most markets, results from standardized test procedures are applied to determine greenhouse gas emissions that are the foundation for regulations or taxes [160]. In Europe, the assessment of real drivingemissions (RDE) has been introduced in order to determine pollutants from ICE vehicles [161].

As reviewed from different studies by Pandian et al., vehicle size and weight influence the fuel use, which as a result increases the $\mathrm{CO}_{2}$ emissions [162]. There might be a relation of other pollutants to vehicle weight, e.g. regarding particulate matter and nitrous oxides for diesel engines, but these are also strongly determined by other factors like the engine type, the applied exhaust gas treatment or the driving situation $[162,163]$. However, non-exhaust particle emissions, such as tire wear, increase with vehicle weight [162].

Several research studies have been published on physics-based approaches to determine mass-induced effects on a vehicles' fuel consumption $[65,157,158,161,164-166]$. One important factor is the evaluation of drivetrain efficiencies to derive the relation between energy intake and output. For combustion engines, Willans-lines display this relation for certain rpm levels (see Fig. 12). They can be derived from the measured values of an engine characteristic graph [157]. Based on the findings by Koffler and Rohde-Brandenburger, a linear relation between fuel consumption and power output can be assumed for low rpm and low power output levels, as those are typical for standardized test procedures. Thus, a small difference in power output, as for example induced by replacing one component by a lighter structure, leads to a linear decrease in fuel consumption [157]. However, this approach is limited to primary mass savings.

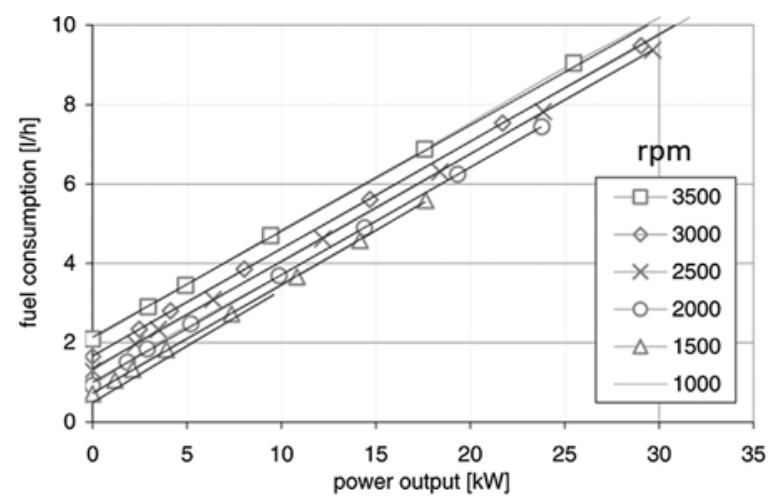

Fig. 12. Willans lines and resulting trendlines of a $1.4 \mathrm{~L}$ turbocharged gasoline engine (90 kW) for low output and low rpm [157].

Electric vehicles (EVs) and hybrid drivetrains pose special challenges in the assessment of mass-induced effects on environmental impacts. Unlike most conventional vehicles, energy recovery occurs during deceleration stages [167]. The amount of reclaimed energy during braking influences the mass-related energy demands and thus requires a more sophisticated analytical approach. A review of standardized test procedures for EVs shows the relation between vehicle mass and energy demand that is around $5.6 \mathrm{Wh} / \mathrm{km}$ per 100 $\mathrm{kg}$ of additional weight [168]. The scenario gets even more complex for hybrid drivetrains, as driving modes need to be considered to determine use stage emissions. 

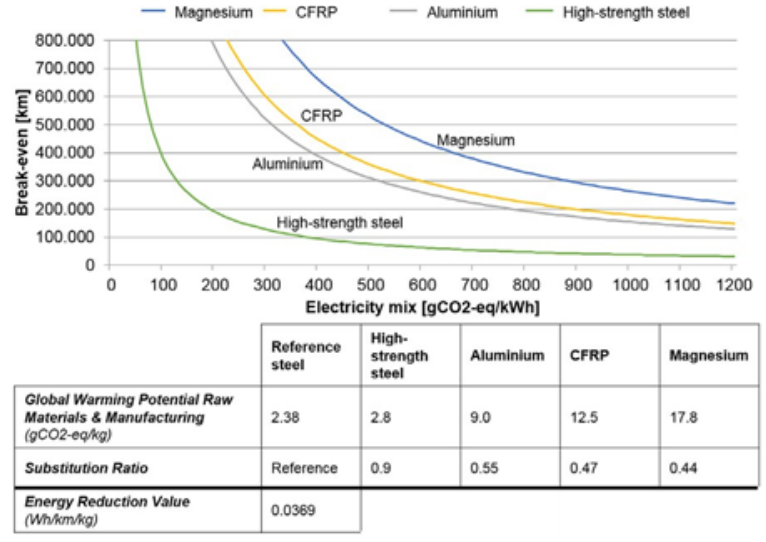

Fig. 13. GWP break-even analysis between raw materials, manufacturing and use stage of electric vehicles for different material substitution scenarios when replacing conventional steel [8].

In comparison to conventional drivetrains, LCA studies calculating use stage energy demands of EVs show a large variety of parameters influencing powertrain efficiency [22,167,169- 172]. Furthermore, the background system for vehicle operation influences the environmental impacts of electric vehicles significantly. Egede provides a framework to consider influencing factors on the energy demand during the electric vehicle use stage [173], elaborated in Ref. [8]. With regard to lightweight structures, the approach supports analysing and evaluating the interdependencies of the foreground and background system. Fig. 13 shows a break-even analysis of global warming potential taking into account raw materials, manufacturing and use stage. Thereby, raw materials and manufacturing impacts are set into relation of the GHGemissions resulting from electricity generation for energy to charge an electric vehicle. Taking Germany as an example the $\mathrm{CO}_{2}$-eq intensity, depending on the electricity mix, was reported with $527 \mathrm{gCO}_{2}$-eq per kWh for 2016 by the German Environment Agency. Consequently, the break-even point for replacing conventional steel with HSS is at about $90,000 \mathrm{~km}$, whereas the break-even point for magnesium is at around $450,000 \mathrm{~km}$. In such a way, the chart supports the development of general knowledge and recommendations. With an increasing share of renewable energy sourced electricity being used for charging electric vehicles, the environmental benefit of lightweight design by materials decreases. However, secondary effects arising from the battery size as well as from the application of renewable energy during material extraction and manufacturing are not considered in the graph. In addition, like conventional break-even charts, the visualisation is generally limited to one environmental indicator or impact category. Thus, this visualisation has limitations with respect to understanding problem shifting between different environmental impact categories.

Further studies with a focus on trade-offs between environmental impacts from raw materials, manufacturing and primary effects on the use stage of automotive lightweight structures focus on steel-intensive car bodies [174] as well as composites and hybrid materials in ICE- and electric vehicles [175]. For EVs, only for two out of six studied lightweight components that had been designed within a research project, additional GWP burdens from raw materials and manufacturing could be compensated during the use stage [175].

Luk et al. provide a comprehensive review on methods enabling life cycle assessment of lightweight structures with respect to different powertrains. They identify a detailed understanding of primary and secondary effects to be crucial for deriving robust decisions on the environmental impacts of lightweight structures [176]. Secondary effects of lightweight structures encompass all weight reductions that are enabled as a follow-up measure in the course of executing a lightweight strategy. The assessment of secondary effects requires a deep system understanding of the respective product, as shown for example by Luedeke et al. [177]. Alonso et al. assess secondary weight savings based on a broader model of the vehicle structure and solution space for relevant redesigns [165]. Depending on the regarded vehicle subsystems, secondary mass savings range between 0.12 and

$0.77 \mathrm{~kg}$ per $\mathrm{kg}$ of primary weight saving. According to Refs. [157] and [178], adaptions in gear ratio and displacement to maintain driving performance after decreasing weight could double the achievable fuel reduction for ICEs in the standardized NEDC test. Delogu and Del Pero et al. derive primary and secondary improvements in the use stage for different vehicle classes and test procedures for both gasoline and diesel vehicles [161,164]. Hofer et al. as well as Lewis et al. provide a comparison of effects from decreasing weight on battery electric vehicles and conventional vehicles using a physical modelling approach [170,179].

González Palencia et al. performed several studies on the impact of lightweight structures on vehicle fleets. In the case of light duty fleets, the impact of lightweight structures is seen as a subordinate measure in comparison to the introduction of low emission drivetrains [180]. Due to lower fuel consumption, lightweight vehicles might accelerate the diffusion of fuel cell and battery electric vehicles. This would lower the requirements for a new infrastructure for power generation and hydrogen production, enabling faster market diffusion $[181,182]$

\subsection{Aerospace}

The International Civil Aviation Organization ICAO comprehensively assessed the environmental impact of the aviation sector [183]. Lopes [184] performed an LCA of an aircraft model Airbus A330-200. In his research, he presents a relatively complete life cycle inventory regarding the materials required to manufacture the aircraft. A similar study is provided by Timmis et al. [46]. The authors analysed the introduction of CFRP within the aviation sector to reduce aircraft fuel consumption. They suggest that the application of composite materials, primarily CFRPs, can contribute to a reduction of the aircraft weight of about $20 \%$ compared to an aluminium alloy structure. Applying the LCA methodology, a business-as-usual scenario for 2015 and a lightweight scenario for 2050 were compared. A $14-15 \% \mathrm{CO}_{2}$ emission reduction was estimated for the 2050 lightweight scenario compared to the 2015 business-as-usual scenario. Achternbosch et al. show that a weight reduction of $30 \%$ could be achieved when substituting aluminium with CFRP for an airplane body structure. However, fuel savings in service life time only decreased by $4 \%$ as only the body was adapted [96]. Studies analysing the cost and environmental impact of introducing alternative propulsion systems (electric and hybrid systems) within the aviation industry are scarce. Johanning studied electric and hydrogen powered aircrafts, focusing on the evaluation of the potential amount of energy required by each of the technologies without considering the production of essential components such as the battery system [185].

Kara et al. performed a comparative life cycle assessment of an aircraft component produced from titanium and CFRP. The cumulative energy demand (in that case referred to as embodied energy) during the entire life cycle in different operation scenarios (20,000 flights) has been determined. CFRP components perform slightly better, when aircraft fuel consumption is included in the system boundary and perform worse when it is excluded [186].

\subsection{Machine tools}

In comparison to automotive and aerospace applications, the evaluation of use stage benefits for lightweight structures in manufacturing shows both similarities and differences. Similar to transport, lightweight structures enable an increase of energy efficiency when applied to moveable structures [27]. Examples are shown by Kussmaul et al. for the introduction of CFRPs in structural machine elements [50] or by Bischoff et al. for the case of a lightweight robot arm [49]. According to Kroll et al., primary and secondary effects can be distinguished [27]. Fig. 14 shows potential effects on machine tool servo drives. 


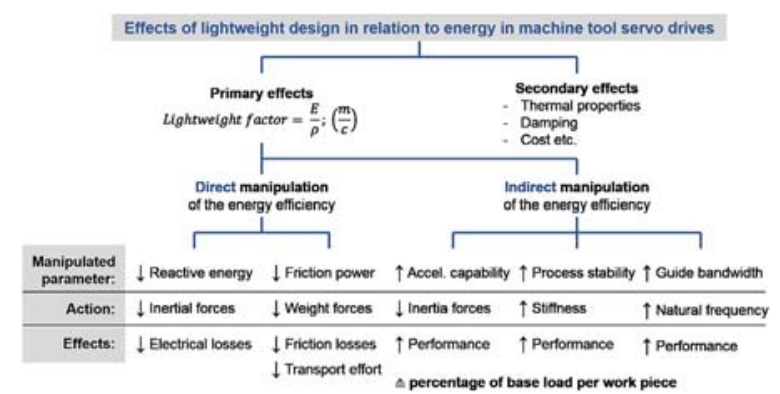

Fig. 14. Summary of the effects of lightweight design measures on the energy efficiency of machine tool servo drives [27].

Potential efficiency gains in the use stage could compensate material and manufacturing related impacts during a machine's lifetime. Similar to vehicle structures, the effects of weight reduction on energy demands in the use stage are determined by assessing the influence of mass on machine loads. Kroll et al. show the load dependent decrease of energy losses from a lower weight. The $x$-stand of a 5-axis milling centre serves as a sample case. As the x-stand is connected to the machine bed, only the $x$-axis itself benefits from weight reduction. By reducing the moving mass through topological optimisation and material substitution, electrical energy losses of installed servo drives could be reduced by $16-47 \%$, depending on the feed and acceleration levels. A weight reduction of $29 \%$ moving mass compared to the original design of the $\mathrm{x}$-stand was achieved [27].

\section{End-of-life and recycling of lightweight structures}

End-of-life treatment - incorporating reuse, remanufacturing and recycling into the life cycle - is an important environmental impact mitigation strategy. End-of-life treatment enables products or materials to be recirculated into the production stream and consequently to a secondary use stage. Hence, primary material production decreases. Lower embodied energy of the secondary products or materials leads toa decrease of environmental impacts [187]. This is true for average secondary material flows that go through multiple use cycles. However, virgin material needs to be processed first in order to generate secondary material flows in required quantities. For example, primary aluminium requires a specific production energy of $93 \mathrm{MJ} / \mathrm{kg}$, while secondary aluminium only requires $6 \mathrm{MJ} / \mathrm{kg}$ [188]. In addition, disposal can be reduced through the recirculation of secondary materials and therefore the necessity of landfilling diminishes [187].

The collection and reprocessing of materials causes environmental impacts, such as the energy required to separate materials [187]. The use of hybrid materials to achieve lightweight structures, such as fibre/textile composites or multi-material structures that apply joining technologies to combine different materials on a component level, can also inhibit recycling $[189,190]$. Composites and multi-material structures are also more difficult to be separated with existing disassembly and recycling technologies. Therefore, the material recovery rate and the quality of the recycled material will potentially decrease and more waste will be generated in the end. Fig. 15 shows an influence diagram that illustrates these interdependencies. Multimaterial structures allow vehicles to be designed with less weight and therefore lower environmental impacts during the use phase (balancing loop). However, the introduction of multi-material structures can have negative effects on the recycling efficiency and lead to more waste and additional environmental impacts (reinforcing loop).

Recycling efforts might also help to achieve compliance with legislative targets. For example, the European directive on end-of-life vehicles (ELV) dictates that at least $95 \%$ of the mass of end-of-life vehicles should be reused and recovered, and at least $85 \%$ should be recycled (the rest may be incinerated with energy

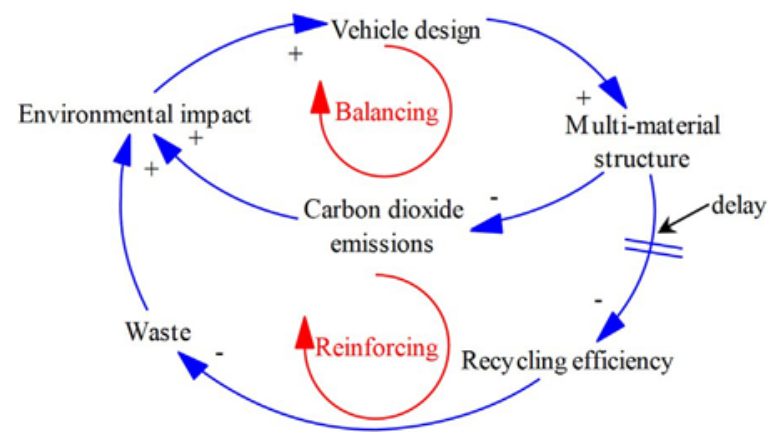

Fig. 15. Balancing loop of $\mathrm{CO}$ 2 emissions impact and reinforcing loop of waste produced [33].

recovery, for example) [191]. As shown in Fig. 16, using the example of a substitution from an aluminium reference to a magnesium structure in a vehicle, recycling rates at the end-of-life for a lightweight structure significantly influence the environmental performance of that structure over its life cycle. Low recycling rates could neutralize use stage benefits for GHG emissions gained through the reduction of weight [192]. However, for an entire vehicle, the contribution of the end-of-life stage to its overall environmental impact is comparatively low. Thus, potential trade-offs between life cycle stages need to be evaluated [193].

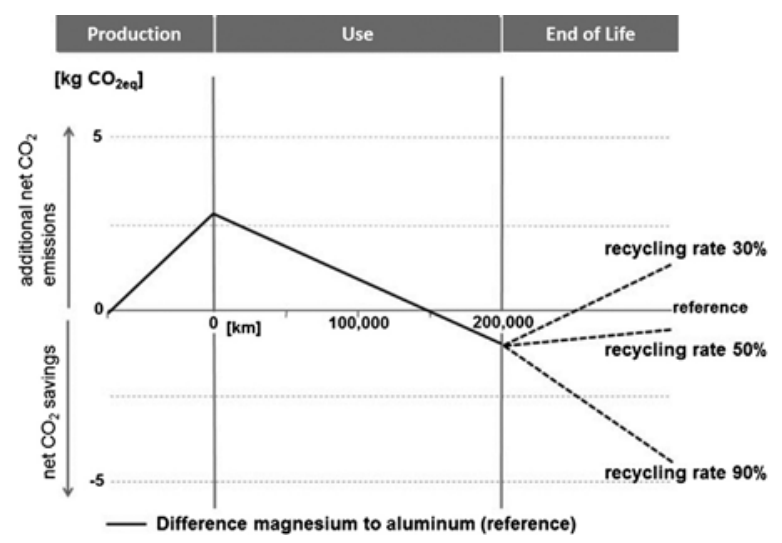

Fig. 16. Relative influences of different recycling rates on the environmental life cycle balance of a vehicle magnesium component compared to an aluminium reference with $90 \%$ recycling rate [192].

Considering these developments, new challenges in the engineering of the lightweight structures emerge. In the case of vehicles, the state-of-the-art in industrialized countries is represented by open and closed loop recycling by shredding, sorting and separation [194]. From a technological perspective, lightweight structures demand the development of new end-of-life processes, such as the separation of multi-material structures [189] or the large-scale treatment of new materials like fibre-reinforced plastics [142,195]. Most studies to date exclusively tackle the material recycling of lightweight structures, while reuse and remanufacturing are typically excluded [196]. From a business perspective, opportunities for economically viable applications of secondary materials need to be identified. In the case of new materials, carbon fibre recycling by pyrolysis can save up to $90 \%$ of the energy required to produce virgin material [197]. However, this only holds for a high quality secondary material that allows the replacement of virgin material. Matrix material is lost during theprocess. As stated by Geyer et al., the environmental impact of recycling is determined by evaluating the efforts of recycling in relation to the actual avoided landfill and avoided primary production for the secondary application [187]. As presented by Soo et al., a delay in environmental impacts and resulting trade-offs is observed between life cycle stages ([33], see Fig. 15). Thus, 
quality considerations of recycled materials as well as temporal effects regarding material stocks need to be considered.

\subsection{Quality losses in recycling}

The mixing or contamination of materials to be recycled leads to the aforementioned challenge of downcycling, which "... can be defined as the reprocessing of EOL waste into products of inferior quality, compared to the primary material ... " [198]. Especially non-metals, such as minerals from construction, and plastics from most technical products, are not recycled in such a way that the output material can offer the functionality and properties of primary materials [198]. Even metals are often downcycled. For instance, aluminium is used as an alloy containing silicon, copper or zinc. When remelting the aluminium alloy, these elements cannot easily be controlled, leading to cast alloys of lower quality that cannot be used in the original lightweight structure application [199]. Down-cycling also happens for steel. Ohno et al. discuss obstacles in the sorting of steel qualities and recycling with regard to the recovery of elements. Overcoming these obstacles could reduce primary material production considerably. For instance, a Japanesefocused case showed that improved sorting could lead to a recovery of $8.2 \%$ of the total market demand of alloyed material $[200,201]$.

\subsubsection{Impact of new joining techniques}

When introducing new materials or increasing the material variety, new joining technologies can enable the combination of different materials. In the case of lightweight vehicle structures, this could encompass adhesive bonding [202] or new forms of mechanical joining [203]. In the case of structural elements, a good mechanical performance of joints enables certain use applications, but coincidently hinders separation at the end-of-life. This effect influences the economic feasibility of recycling as discussed by Sakundarini et al [118]. In some cases, further materials are introduced through new joining techniques [189]. One example is the application of rivets when joining metals and FRPs [127]. A decrease of actual recycling rates further occurs from an increasing variety of different joints applied. Table 3 provides an overview of joining techniques for vehicles between different metals, polypropylene and CFRPs [189].

Table 3

Multi-material joining techniques in automotive applications [189].

10

\begin{tabular}{|c|c|c|c|c|c|c|}
\hline & $\begin{array}{l}\text { Mild } \\
\text { Steel }\end{array}$ & AHSS & $\begin{array}{l}\text { Alu- } \\
\text { minium }\end{array}$ & $\begin{array}{l}\text { Mag- } \\
\text { nesium }\end{array}$ & $\begin{array}{l}\text { Poly- } \\
\text { propy- } \\
\text { lene }\end{array}$ & CFRP \\
\hline $\begin{array}{l}\text { Mild } \\
\text { Steel }\end{array}$ & $\begin{array}{l}\mathrm{abc} \\
\mathrm{d} \mathrm{e} * \\
\mathrm{fg}^{*}\end{array}$ & $\begin{array}{l}\mathrm{abc} \\
\mathrm{d} \mathrm{e} \\
\mathrm{f}^{*} \mathrm{~g}^{*}\end{array}$ & $\begin{array}{l}a b c \\
d^{*} e^{*} \\
f^{*} g\end{array}$ & $\begin{array}{l}a b c \\
d^{*} e^{*} \\
f^{*} g^{*}\end{array}$ & $\mathrm{bc} \mathrm{e}^{*}$ & $\mathrm{bc} \mathrm{e} *$ \\
\hline AHSS & & $\begin{array}{l}\mathrm{abc} \\
\mathrm{de}^{*} \\
\mathrm{fg}^{*}\end{array}$ & $\begin{array}{l}a b c \\
d^{*} e^{*} \\
f^{*} g\end{array}$ & $\begin{array}{l}a b c \\
d^{*} e^{*} \\
f^{*} g^{*}\end{array}$ & $b c e^{*}$ & $\mathrm{bc} \mathrm{e} *$ \\
\hline $\begin{array}{l}\text { Alu- } \\
\text { minium }\end{array}$ & & & $\begin{array}{l}a b c \\
d e^{*} \\
f g\end{array}$ & $\begin{array}{l}a b c \\
d^{*} e^{*} \\
f^{*} g^{*}\end{array}$ & $\mathrm{bc} \mathrm{e}^{*}$ & $\mathrm{bc} \mathrm{e} *$ \\
\hline $\begin{array}{l}\text { Mag- } \\
\text { nesium }\end{array}$ & & & & $\begin{array}{l}a b c \\
d^{*} e^{*} \\
f^{*}\end{array}$ & $b c e^{*}$ & $\mathrm{bc} \mathrm{e} *$ \\
\hline $\begin{array}{l}\text { Poly- } \\
\text { propy- } \\
\text { lene }\end{array}$ & & & & & \multirow[t]{2}{*}{$\mathrm{bc} \mathrm{e}^{*}$} & $\mathrm{bce} \mathrm{e}^{*}$ \\
\hline CFRP & & & & & & $b c e^{*}$ \\
\hline $\mathrm{a}$ & $\begin{array}{l}\text { TIG, MIG } \\
\text { welding }\end{array}$ & $\mathrm{e}$ & $\begin{array}{l}\text { Ultrasonic spot } \\
\text { welding }\end{array}$ & & \multicolumn{2}{|c|}{$\begin{array}{l}\text { Carbon Fibre } \\
\text { Reinforced } \\
\text { Polymer }\end{array}$} \\
\hline $\mathrm{b}$ & $\begin{array}{l}\text { Adhesive } \\
\text { bonding }\end{array}$ & $\mathrm{f}$ & Laser welding & & \multirow{3}{*}{\multicolumn{2}{|c|}{$\begin{array}{l}\text { S Advanced High } \\
\text { Strength Steel } \\
\text { Introduce } \\
\text { additional } \\
\text { materials } \\
\text { Not in large- } \\
\text { scale production }\end{array}$}} \\
\hline $\mathrm{c}$ & $\begin{array}{l}\text { Mechanical } \\
\text { fastening }\end{array}$ & $\mathrm{g}$ & $\begin{array}{l}\text { Friction stir spo } \\
\text { welding }\end{array}$ & ot & & \\
\hline d & $\begin{array}{l}\text { Resistance } \\
\text { welding }\end{array}$ & & & * & & \\
\hline
\end{tabular}

6.1.2 Metals

In the case of steel, recycling is a vital part of the global supply chain: approximately one third of the annual steel production originates from recycling [204]. Yet, many impurities enter steelwaste flows in recycling routes during electric arc furnace (EAF) remelting processes. Without proper sorting, the degree of carbon or aluminium introduction in the EAF step may create obstacles for steel recycling, as the flow of unintentionally recycled alloying elements represents between 7 and $8 \%$ of the world's annual EAF consumption [200]. Ohno et al. [201] point out the potential environmental and economic benefits of sorting steel qualities in end-of-life vehicles.

Aluminium experiences open loop recycling with a cascade recycling approach. This relates to the loss of inherent properties and the necessity for an impurity dilution step with primary materials. In general, secondary aluminium has a higher silicon content that is acceptable for application to casting products [71]. However, aluminium from recycling post-use scrap is typically not applied in structural components. Improvements in the sorting of aluminium alloys from end-of-life vehicles to enable a secondary use as a replacement for primary wrought material has been discussed by Paraveskas et al. as well as Cui et al. [199,205]. Preserving the quality of the scrap streams by compositionally closed recycling loops can offer significant environmental benefits [199], but only at considerable logistical and economic cost. Solid state recycling can reduce quality related losses compared with smelting processes, while also leading to enhanced mechanical properties [206]. The sorting of magnesium from end-of-life scrap is possible using different technologies, but economic incentives are lacking to introduce them to the market. Thus, magnesium usually serves as an additive for a secondary aluminium alloy. Further applications of secondary magnesium include the desulfurisation of steel as well as the production of non-structural products [192].

\subsubsection{Fibre-reinforced plastics}

Fibre reinforced plastics usually undergo severe quality losses in recycling. Paints and metallic inserts create complex structures that pose challenges to the recycling processes. In addition, a large heterogeneity in composition between materials is observed. This complicates collection and separation [207]. Another basic challenge is the liberation of homogeneous particles from the composite material. Composite recycling is hindered both by the fibre and other types of reinforcement, and by matrix or binders, in particular the thermoset type [208].

In the case of glass fibre, mechanical recycling can be performed at an industrial scale [209]. Recyclates are usually short fibres or powder in contrast to clean, long virgin fibres. This applies to carbon fibres as well. Mechanical recycling processes result in shortened fibre length and reduced mechanical properties, e.g. strength and strain properties, so that recycled carbon fibres are only available for lower value applications compared to virgin fibres [207,209-212]. Due to the higher value of carbon fibres, more complex recycling processes can be applied. Pyrolysis [142] and fluidised bed methods [213] show promising results in terms of achieving quality targets in carbon fibre recycling. According to reports from industry, $5-10 \%$ of the energy required for virgin fibre production is required for the recovery of CFRP waste [197]. Like mechanical recycling, these methods also suffer from the low quality of recycled carbon fibres due to insufficient surface properties $[142,196]$. On the other hand, quality conditions of recycled carbon fibre strongly correlate with pyrolysis conditions. Small-scale processes usually result in recovery of more than $80 \%$ of original stiffness and $90 \%$ of original strength, allowing usage of recycled fibres in structural applications [196]. Longana et al. have proposed the High Performance Discontinuous Fibre (HiPerDiF) method, which permits production of aligned short fibre composites in multiple loops while retaining mechanical properties [212]. Other technologies under development for fibre-reinforced composites include high voltage fragmentation [214], hydrolysis, solvolysis using supercritical water [215], and biotechnological processes [195]. The state of research in the recycling of fibre-reinforced plastics has been addressed in several publications [142,207,208,216-218]. Suitable applications for secondary materials from various recycling routes exist. However an economically feasible setup of manufacturing value chains based on secondary composite materials requires significant future research [142].

\subsection{System expansion}

The recycling of engineering materials for lightweight structures might show challenges with regard to a larger industrial scale. This concerns 
overall recycling rates as well as temporal and spatial availability of secondary material streams for secondary applications. While metals such as aluminium can be recycled many times, the average recycling rate in the United States during 1972 to 2007 was, on average, only $25 \%$ [219]. There is ample evidence from around the world that many recyclable materials have not been recycled to their ultimate potential. Furthermore, the economics of contaminant removal usually lead to downcycling of the materials such as the specialized metal alloys used in lightweight structures [220]. Consequently, it should be expected that even once lightweight materials become available for recycling, it is unlikely that new lightweight structures will be manufactured by recycling discarded lightweight structures unless large economic investments are made, e.g. to create separate collection and production infrastructures to avoid material mixing and contamination [220]. Even if all lightweightstructures could be produced from recycled material, the availability of recycled material will lag behind production needs for decades to come. For example, CFRP is currently undergoing a dramatic increase in demand. Adopting a top-down approach toconsiderinputand outputflowsforaspecific period and system boundary, and a bottom-up approach to measure the occupation of CFRP in the commercial aeronautic sector, Lefeuvre et al. anticipate the use stocks of CFRP. Only 34 tons of CFRP are estimated to be available for recycling from a total amount of 1.2 million tons in 2050 . For the year 2015 , the numbers are 13 tons ofCFRP from a total amount of 125 tons[221]. Inghels et al. contribute to method development with a system dynamics approach to estimatethe composition, amount and life span of end-of-life vehicles [222].
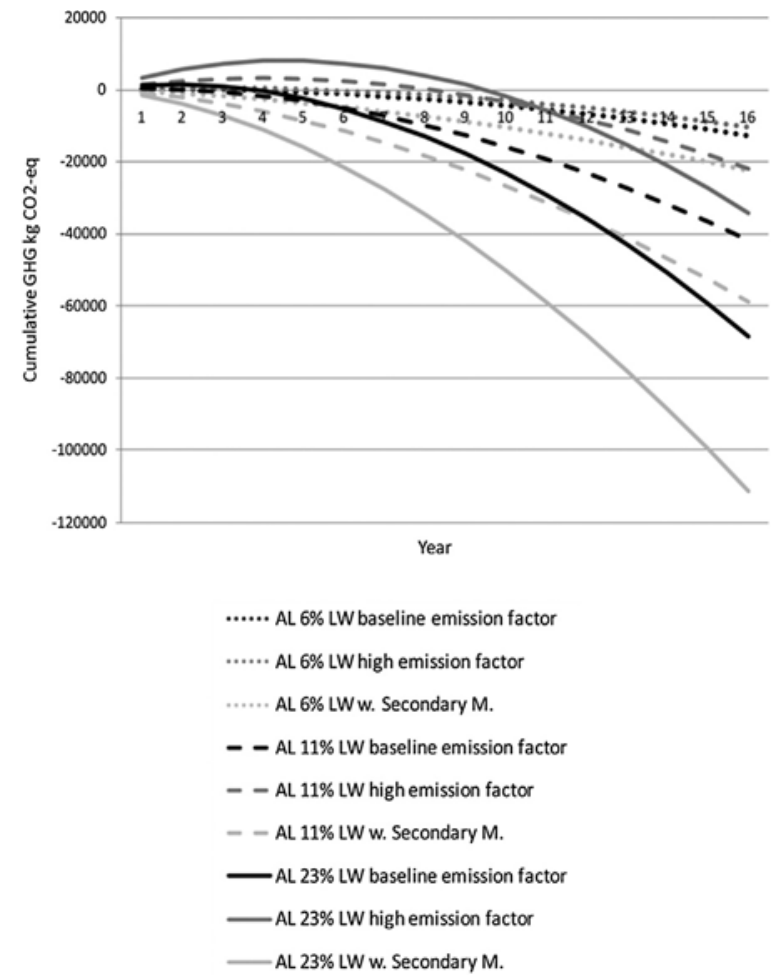

Fig. 17. Cumulative greenhouse gas (GHG) emissions payback from different aluminium lightweight scenarios ( $6 \%, 11 \%, 23 \%$ weight reduction) for vehicles compared to a steel-intensive vehicle (baseline scenario) [62].
Based on a detailed life cycle and material model, Kim et al. studied life cycle greenhouse gas emissions from producing lightweight vehicles using aluminium and high strength steel with respect to recycling systems. Compared to a baseline vehicle made from low-alloyed steel, different lightweight scenarios $(6 \%, 11 \%$ and $23 \%$ weight reduction compared to a reference passenger vehicle) based on the introduction of aluminium from primary and secondary sources are discussed. Fig. 17 shows that if aluminium material production does not increase over time, a vehicle with a major weight reduction $(23 \%)$ would need to be driven for four to ten years before the production emissions are offset by lower fuel consumption. If material production impacts increase, then the system-level payback times can extend significantly beyond ten years, e.g. if the aluminium is made from a high emissions source [62]. Such factors demonstrate the urgency of achieving low emissions in production and high recycling rates without down-cycling. If the same lightweight vehicle could be produced with purely recycled materials, the greenhouse gas payback is well less than a year (see Fig. 17) [62].

\subsection{Life cycle oriented engineering tools in end-of-life}

LCE supports the analysis of end-of-life of lightweight structures in numerous dimensions. In terms of goal and scope definition, Frees et al. investigate the crediting of aluminium regarding the replacement of primary or secondary materials with respect to demand and disposal rates [223]. As for inventory building, Shuaib et al. as well as Howarth et al. contribute to the assessment of energy demands of different recycling methods $[209,210,214]$. Rybicka et al. classifiy manufacturing waste and provide a method of systematic data gathering of composite waste from manufacturing [224]. Gala et al. discuss an approach promoting a mixture of virgin and recycled materials and considering the change in material properties while undergoing recycling processes [225]. Liu et al. review available models and optimisation techniques in composite recycling, for example by linking product and process models as well as secondary applications [216]. Castro et al. analyse the influence of thermodynamic constraints when recycling different metals [226]. Keivanpour et al. contribute a description of special boundary conditions and business perspectives in aircraft recycling. An optimisation framework targeting managerial decisions such as global logistics, network structure, dismantling strategies, performance management, and management of the value chain is presented [227]. The work of Dong et al. seeks understanding of the influence of aerospace CFRP waste flows [228]. In terms of supporting engineering activities, Sakundarini et al. provide a material selection approach incorporating the challenges of recyclability when designing multi-material structures (see [118]). Le Duigou focuses on methods to optimise the application of secondary aluminium [121]. Pompidou et al. elaborate on methods to foster a collaboration between productrelated engineering and the recycling industry [229].

\section{Future research directions}

Making products lighter can improve product performance and reduce cost while showing the potential to reduce energy and resource consumption. However, lighter products do not always go hand in hand with lower environmental impacts. Recent research calls for a stronger definition of sustainability while considering the absolute boundaries of the earth's life support system [2]. Therefore, life cycle engineering has to refocus and return to its starting point, where it was driven by environmental concerns. LCA is already a well-established method to assess environmental impacts. Further research and development of the LCA methodology, models and data is ongoing. This paper has discussed life cycle engineering of lightweight structures based on LCA and reviews numerous studies within different fields of application. With 
respect to the life cycle stages, the following future research directions can be identified:

- Extraction and production of lightweight materials: The review shows that applications in the automotive industry dominate today's literature. A wide variety of LCE studies look at established metals, e.g. steel, aluminium, magnesium and fibre-reinforced materials. Less work has been identified for other lightweight metals such as titanium as well as for multi-material structures combining different metals and plastics. The data presented in these papers is often case specific and based on various assumptions that are not always documented. Thus, further emphasis should be given to developing life cycle inventory data for a wider range of lightweight materials. Depending on ore grade, production routes and technological maturity, the extraction and production of lightweight materials may be energy-intensive. As the share of renewable energies and process efficiencies in materials production increases, environmental impacts can differ significantly over time and geographic regions, and thus should be incorporated in the LCE decisionmaking. Bio-based materials can realize lightweight structures with lower environmental impact. However, more research needs to be undertaken to investigate the benefits on a case-by-case basis.

- Manufacturing of lightweight structures: Further research is required to enable large-scale production of lightweight structures. In addition, technologies to improve form and topology are needed, as one goal in LCE is to use less material to provide a certain functionality. Thus, technologies like additive manufacturing and further processes to implement new design approaches, such as lattice structures, should be investigated [145]. In addition, further research is required to build quantitative models and databases (e.g. CO2PE! [230] and ecoinvent [231]), that are accessible to the life cycle engineering community.

- Use stage: For certain products, such as vehicles, the motivation to introduce lightweight structures is often linked to energy or fuel reduction during operation. However, if the product is electrified (e.g. electric vehicles), the resulting emissions strongly depend on the electricity mix as part of the background system. As a result, there is no general recommendation as to whether a lightweight structure is environmentally beneficial. Thus, more emphasis has to be put on the LCE of lightweight structures, which includes variability due to technological, inter-individual, geographical and temporal aspects. For example, lightweight structures may have a longer or shorter lifetime, or require new technologies for repair. Furthermore, studies in support of LCE for lightweight structures often involve a comparison of product systems where a reference structure is replaced by a lightweight structure. The comparison neglects the fact that especially structures based on multi-material or hybrid material systems enable the integration of further functions such as thermal or electrical conductivity. Thus, the handling of multifunctionality in LCE of lightweight structures is important.

- End-of-life and recycling of lightweight structures: Challenges resulting from the end-of-life stage are often addressed related to lightweight materials, e.g. fibre-reinforced plastics, and with a focus on automotive applications. However, mainly the development of new process technologies is addressed, whereas the introduction of recycled material to secondary applications is identified as a research demand. One reason is the limited availability of recycled material. Further research should encompass the introduction of secondary material flows from lightweight materials in new applications based on viable business models. End-of-life treatment is currently not a primary topic in the aerospace industry. The main reason for this are the long life cycles of aircrafts and the absence of legal/regulatory requirements such as those in the automotive sector. It is envisaged that the recycling of aircraft components and end-of-life management in general will become more important in the future due to regulation and a growing number of scrapped airplanes.

- With regard to methodological aspects supporting LCE of lightweight structures, five major future research directions are derived.

- First, this review shows that lightweight structures are often implemented using a combination of different lightweight levers. Whether a lightweight structure is beneficial from an environmental perspective often depends on the application and usage scenario. Consequently, the environmental impact is the result of the interplay of different systems (e.g. raw material extraction systems and manufacturing systems), with the energy system having strong interdependencies with all other systems. As a result, future LCE activities have to handle not only one product system, but also a number of independent, interacting systems. Thus, there is not only one foreground system, but a number of foreground systems that have to be engineered in an integrated manner. This perspective can belinked to the concept of "system of systems" engineering [232]. In Ref. [233] Lukasik asked the question: what is "[ . . . ] the endpoint of engineering practice, what it is that engineers engineer." Our answer is: multiple, interacting systems that fulfil technical and economic requirements while at the same time do not damage the ecosphere, but preferably contribute to protect the ecosystem, human health, and resource availability. Therefore, to engineer lightweight structures with regard to life cycle demands, an approach is required that supports the quantitative description of the inputoutput relationships for all relevant unit processes, integrates information across different systems as well as spatial and temporal scales, computes the impact of lightweight levers on environmental areas of protection, and reduces time and effort to evolutionarily or revolutionarily (re-)design systems and to permit system optimisations. Thus, building upon the concept of integrated computational materials engineering (ICME) [234], we propose to further direct research activities towards exploring an integrated computational life cycle engineering (icLCE). With icLCE aiming at simultaneously designing and optimising the relevant, interlinked systems in the foreground, the approach goes beyond an exclusive assessment of environmental impacts. The complexity of the scope requires advances in computational techniques allowing the coupling of computational models with respect to the spatial and temporal scales. Furthermore, methods such as multi-attribute optimisation and uncertainty analysis are required.

- Second, most of the reviewed studies focus on an eco-efficiency approach with climate change being the most frequently represented environmental impact category. With the identified need to relate LCE activities to absolute sustainability requirements comes a need to transition from the traditional relativistic perspective of LCA ("Is the use of lightweight materials better than conventional materials from an environmental perspective?") to an absolute perspective ("Is the use of lightweight materials environmentally sustainable?") [235]. This includes addressing the total environmental impact related to increasing production volumes needed to meet a growing population and increasing affluence in the future. This is a new field of research, and proposals have been made on how to introduce an absolute perspective into LCA in the normalisation [236] or weighting steps [237] of life cycle impact assessment. More normative choices are involved, regarding how to divide the remaining environmental space between lightweight constructions and the many other technologies used to meet human needs [238]. Thus, future research in the life cycle engineering of lightweight structures should be centred on methods and tools that support reducing the total environmental impact. Incorporating the topdown perspective can support reducing complexity and steering an icLCE-based engineering of systems. The top-down perspective supports identifying the most relevant (foreground) systems and pinpoints the most promising mitigation options (e.g. based on the IPAT equation and the Kaya identity). 
- Third, as shown in this paper, a significant body of research studies has focused on the benefits of lightweight levers in the use stage against the additional environmental burden of extraction and producing lightweight materials as well as manufacturing and recycling. Another, less discussed issue requiring modelling is the more intense use of lightweight products. Clearly, vehicles can accelerate faster and planes can fly further when carrying less weight. But will they? For example as part of an icLCE approach, models are needed to understand the true demand for lightweight products and how they will impact the systems into which they are introduced [239]. For instance, models developed in Ref. [240] show that policy incentives in the

U.S. automotive sector meant to promote lightweight design have structural incentives resulting in much of the benefit to be turned towards higher performance vehicles rather than lower emissions vehicles. The study furthermore showcased that the benefits of design options such as lightweight levers can lead to the production of larger vehicles, which further reduce the environmental benefits of lightweight structures [241].

- Fourth, this review highlights methodological differences to handle end-of-life processes such as recycling and incineration, which produce materialand/orenergyas co-products thatarean input to other product systems. Recycling and incineration are multifunctional processes that both serve for waste treatment and for producing valuable outputs. In an attributional LCA, multi-functionality is accounted for as an allocation, for example according to the (economic) value of each of the services. In contrast, a consequential perspective attempts to model the consequences of the decision that is analysed. This involves an analysis of the expected market responses when the decision is implemented to identify the technologies that will be affected by the decision (the marginal technologies). In a consequential LCA, multi-functionality is accounted for using system expansion, which for recycling in the end-of-life stage is equivalent with crediting the lightweight system with the impacts that are avoided when the recycled materials in the market replace other (often new) materials [242]. The ISO standards prefer the consequential approach of system expansion to allocation when possible. The European Commission's LCA Guideline differentiates between different goal situations. When the study concerns large-scale decisions with implications not just for the foreground system, but also the background system (e.g. waste management system, energy system, material production industries and different temporal and geographic regions), a consequential perspective should be applied. On the other hand, when decision implications are mostly limited to the foreground system, the recommendation is to use attributional LCA. For common recycling processes, the guideline makes an exception and recommends crediting with avoided impacts also for small scale decisions [242]. If different modelling approaches are applied, results from small-scale studies cannot necessarily be upscaled to make decisions on a large scale. From a strategic perspective, methods and tools are required that support the development of lightweight structures and the related life cycle flow in terms of an integrated product and process life cycle planning [243].

- Fifth, the review underlines the importance of supporting interpretation and decision-making in LCA to use it more effectively for applications in LCE for lightweight structures. In addition, effective LCE for lightweight structures calls for a collaborative approach linking different stakeholders [244]. Common visualisation techniques (e.g.bar charts, Sankey diagrams and break-even charts) as well as common visualisation environments (e.g. presentations using projectors or screens) reach their limits when it comes to communicating the full complexity of LCE for lightweight structures. Here, visual analytics (VA) in combination with laboratory environments are promising research directions to further develop LCE of lightweight structures and beyond [19]. Visual analytics makes use of different "[ . . . ] automated analysis techniques with interactive visualisations for an effective understanding, reasoning and decision making on the basis of very large and complex data sets" [245]. Based on this definition, Fig. 18 proposes an LCE workflow illustrating interfaces between data acquisition, modelling, visualisation and interpretation, and knowledge generation [246]. For the case of lightweight structures, an interdisciplinary collaborative approach capturing the manifold interdependencies between design, manufacturing and LCE has been proposed [11].

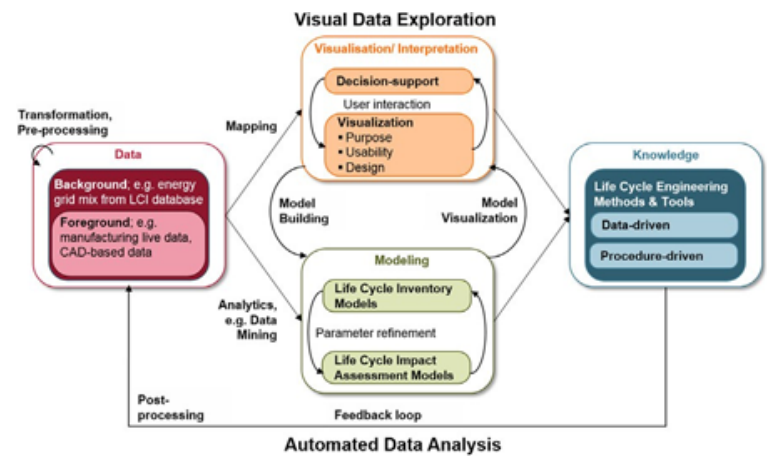

Fig. 18. Visual analytics-based LCE according to Ref. [246], adapted from Ref. [245]

As one example of the approach of Fig. 18, Fig. 19 shows the Life Cycle Design \& Engineering Lab as a viable research infrastructure of the Open Hybrid LabFactory (OHLF) in Wolfsburg, Germany. The research facility focuses on the development of materials and production technologies for multifunctional lightweight structures. The lab combines task-specific hardware solutions for LCA visualisation, such as multi-display walls (Fig. 19b) and mixed reality (Fig. 19c) as well as the selection of adequate visualisation techniques for LCA results with respect to information demands.

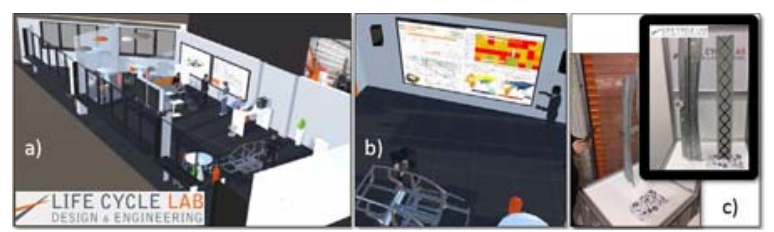

Fig. 19. Life Cycle Design \& Engineering Lab: (a) layout, (b) multi-display wall, (c) augmented reality application.

\section{Acknowledgements}

The authors of this paper gratefully thank the reviewers for their valuable feedback to improve and further develop the review at hand. Furthermore, the authors acknowledge contributions received from numerous active researchers. This includes Profs. G. Reinhart and N. Perry. The authors wish to thank Antal Dér, Felipe Cerdas, Selin Erkisi-Arici, Sebastian Gellrich, Malte Schäfer and Anne-Marie Schlake for their essential help in preparing this paper.

\section{References}

[1] Klein B (2013) Leichtbau-Konstruktion, Springer Fachmedien Wiesbaden, Wiesbaden.

[2] Hauschild MZ, Herrmann C, Kara S (2017) An Integrated Framework for LifeCycle Engineering. Procedia CIRP 61:2-9.

[3] Alting L (1995) Life Cycle Engineering and Design. CIRP Annals - Manufacturing Technology 44:569-580.

[4] Jeswiet J (2014) Life Cycle Engineering. CIRP Encyclopedia of Production Engineering, Springer Berlin Heidelberg, Berlin, Heidelberg757-758.

[5] International Standardization Organization (ISO), ISO 14044:2006 Environmental management - Life cycle assessment - Principles and framework (2006). 
[6] International Standardization Organization (ISO), ISO 14040:2006 - Environmental management - Life cycle assessment - Principles and framework (2006).

[7] Geyer R (2008) Parametric assessment of climate change impacts of automo- tive material substitution. Environmental Science \& Technology 42:6973-6979.

[8] Egede P (2017) Environmental Assessment of Lightweight Electric Vehicles, Springer International Publishing, Cham.

[9] Haes HAU, Heijungs R, Suh S, Huppes G (2004) Three Strategies to Overcome the Limitations of Life-Cycle Assessment. Journal of Industrial Ecology 8:19-32.

[10] Bjørn A, Owsianiak M, Laurent A, Olsen SI, Corona A, Hauschild MZ (2018) Scope Definition. Life Cycle Assess, Springer International Publishing, Cham75-116 .

[11] Kaluza A, Kleemann S, Fröhlich T, Herrmann C, Vietor T (2017) Concurrent Design \& Life Cycle Engineering in Automotive Lightweight Component Development. Procedia CIRP 16-21.

[12] Closing the Loop-An EU Action Plan for the Circular Economy. Communica-tion from the Commission to the European Parliament, the Council, the European Economic and Social Committee and the Committee of the Regions COM, 614(2), 2015.

[13] Potting J, Hauschild MZ (2006) Spatial Differentiation in Life Cycle Impact Assessment: A Decade of Method Development to Increase the Environmen- tal Realism of LCIA. The International Journal of Life Cycle Assessment 11:11-13.

[14] Raugei M, Morrey D, Hutchinson A, Winfield P (2015) A Coherent Life Cycle Assessment of a Range of Lightweighting Strategies for Compact Vehicles. Journal of Cleaner Production 108:1168-1176.

[15] Bovea MD, Gallardo A (2006) The influence of impact assessment methods on materials selection for eco-design. Materials and Design 27:209-215.

[16] Hauschild MZ (2018) Introduction to LCA Methodology. Life Cycle Assess, Springer International Publishing, Cham59-66.

[17] Laurin L, Amor B, Bachmann TM, Bare J, Koffler C, Genest S, Preiss P, Pierce J, Satterfield B, Vigon B (2016) Life Cycle Assessment Capacity Roadmap (Sec- tion 1): Decision-Making Support Using LCA. The International Journal of Life Cycle Assessment 21:443-447.

[18] Cerdas F, Kaluza A, Erkisi-Arici S, Böhme S, Herrmann C (2017) Improved Visualization in LCA Through the Application of Cluster Heat Maps. Procedia CIRP 61:732-737.

[19] Ramanujan D, Bernstein WZ, Chandrasegaran S, Ramani K (2017) Visual Analytics Tools for Sustainable Lifecycle Design: Current Status, Challenges, and Future Opportunities. Journal of Mechanical Design 139:111415.

[20] Hauschild MZ, Rosenbaum RK (2018) in Olsen SI, (Ed.) Life Cycle Assessment, Springer International Publishing, Cham.

[21] e-mobil BW (2012) Leichtbau in Mobilität und Fertigung - Ökologische Aspekte. [22] Helms H, Lambrecht U (2007) The Potential Contribution of LightWeighting to Reduce Transport Energy Consumption. The International Journal of Cycle Assessment 12:58-64

[23] Schmidt JH, Watson J (2014) Eco Island Ferry: Comparative LCA of Island Ferry with Carbon Fibre Composite Based and Steel Based Structures, Aalborg Uni- versitet

[24] Mateus R, Neiva S, Bragança L, Mendonça P, Macieira M (2013) Sustainability Assessment of an Innovative Lightweight Building Technology for Partition Walls - Comparison with Conventional Technologies. Building and Environment 67:147-159.

[25] Zyjewski A, Chróscielewski J, Pyrzowski Ł. (2017) The Use of Fibre-Reinforced Polymers (FRP) in Bridges as a Favourable Solution for the Environment. E3S Web of Conferences 17:00102.

[26] Möhring H-C, Brecher C, Abele E, Fleischer J, Bleicher F (2015) Materials in Machine Tool Structures. CIRP Annals - Manufacturing Technology 64:725748

[27] Kroll L, Blau P, Wabner M, FrieB U, Eulitz J, Klärner M (2011) Lightweight Components for Energy-Efficient Machine Tools. CIRP Journal of Manufacturing Science and Technology 4:148-160.

[28] Möhring H-C (2017) Composites in Production Machines. Procedia CIRP 66:2- 9.

29] Lehmhus D, von Hehl A, Kayvantash K, Gradinger R, Becker T, Schimanski K, Avalle M (2015) Taking a Downward Turn on the Weight Spiral — Lightweight Materials in Transport Applications. Materials and Design 66:385-389.

[30] Ten Broek C, Singh H, Hillebrecht M (2012) Lightweight Design for the Future Steel Vehicle. ATZ Worldwide 114:4-11

[31] Bian J, Mohrbacher H, Zhang JS, Zhao YT, Lu HZ, Dong H (2015) Application Potential of High Performance Steels for Weight Reduction and Efficiency Increase in Commercial Vehicles. Advances in Manufacturing 3:27-36.

[32] Merklein M, Johannes M, Lechner M, Kuppert A (2014) A Review on Tailored Blanks - Production, Applications and Evaluation. Journal of Materials Processing Technology 214:151-164.

[33] Soo VK, Compston P, Doolan M (2015) Interaction Between New Car Design and Recycling Impact on Life Cycle Assessment. Procedia CIRP 29:426-431.

[34] Danilecki K, Mrozik M, Smurawski P (2017) Changes in the Environmental Profile of a Popular Passenger Car over the Last 30 Years - Results of a Simplified LCA Study. Journal of Cleaner Production 141:208-218

[35] Goede M, Stehlin M, Rafflenbeul L, Kopp G, Beeh E (2009) Super Light CarLightweight Construction Thanks to a Multi-Material Design and Function Integration. European Transport Research Review 1:5-10.

[36] Kim SK (2006) Design for Environment (DfE) of Ultralight Aluminum Camshaft Development. Materials Science Forum 510-511:834-837.

[37] Dhingra R, Das S (2014) Life Cycle Energy and Environmental Evaluation of Downsized vs. Lightweight Material Automotive Engines. Journal of Cleaner Production 85:347-358.

[38] Carle D, Blount G (1999) The Suitability of Aluminium as an Alternative Material for Car Bodies. Materials and Design 20:267-272.

[39] Hirsch J (2011) Aluminium in Innovative Light-Weight Car Design. Materials Transactions 52:818-824.
[40] Stodolsky F, Vayas A, Cuenca R, Gaines L (1995) Life-Cycle Energy Savings Potential from Aluminum-Intensive Vehicles. Total Life Cycle Conference \& Exposition 19

[41] Kulekci MK (2008) Magnesium and Its Alloys Applications in Automotive Industry. The International Journal of Advanced Manufacturing Technology 39:851-865

[42] Pervaiz M, Panthapulakkal S, KC B, Sain M, Tjong J (2016) Emerging Trends in Automotive Lightweighting through Novel Composite Materials. Materials Sciences and Applications 07:26-38.

[43] Eckstein L, Ickert L, Goede M, Dölle N (2011) Lightweight Floor Structure with Reinforcements of CFRP and GFRP. ATZ Autotechnology 11:48-52

[44] EADS Deutschland GmbH - Corporate Research Centre, The research requirements of the transport sectors to facilitate an increased usage of composite materials, Part I: The Composite Material Research Requirements of the Aerospace Industry (2004).

[45] Dillingham GL (2011) Aviation Safety - Status of FAA's Actions to Oversee the Safety of Composite Airplanes, United States Government Accountability Office Report.

[46] Timmis AJ, Hodzic A, Koh L, Bonner M, Soutis C, Schäfer AW, Dray L (2015) Environmental Impact Assessment of Aviation Emission Reduction Through the Implementation of Composite Materials. The International Journal of Life Cycle Assessment 20:233-243.

[47] Bachmann J, Hidalgo C, Bricout S (2017) Environmental Analysis of Innovative Sustainable Composites with Potential Use in Aviation Sector - A Life Cycle Assessment Review. Science China Technological Sciences 60:1301-1317.

[48] Yoon HS, Kim ES, Kim MS, Lee JY, Lee GB, Ahn SH (2015) Towards Greener Machine Tools - A Review on Energy Saving Strategies and Technologies. Renewable and Sustainable Energy Reviews 48:870-891.

[49] Bischoff R, Kurth J, Schreiber G, Koeppe R, Albu-Schaffer A, Beyer A, Eiberger O, Haddadin S, Andreas Grunwald G (2010) TheKUKA-DLRLightweight Robot Arm A New Reference Platform for Robotics Research and Manufacturing. ISR 2010 (41st International Symposium on Robotics) and ROBOTIK 2010 (6th German Conference on Robotics) 1-8.

[50] Kussmaul R, Zogg M, Weiss L, Relea E, Jacomet R, Ermanni P (2017) Carbon Fiber Reinforced Polymers for High-Dynamic Testing Machines. Procedia CIRP 66:1-6.

[51] Neugebauer R, Wabner M, Ihlenfeldt S, FrieB U, Schneider F, Schubert F (2012) Bionics Based Energy Efficient Machine Tool Design. Procedia CIRP 3:561-566.

[52] Neugebauer R, Wabner M, Rentzsch H, Ihlenfeldt S (2011) Structure Principles of Energy Efficient Machine Tools. CIRP Journal of Manufacturing Science and Technology 4:136-147.

[53] Ashby MF (2011) Introduction. Materials Selection in Mechanical Design, Elsevier: $1-13$

[54] Allwood JM, Ashby MF, Gutowski TG, Worrell E (2011) Material Efficiency: A White Paper. Resources Conservation and Recycling 55:362-381.

[55] Gutowski TG, Sahni S, Allwood JM, Ashby MF, Worrell E (2013) The Energy Required to Produce Materials: Constraints on Energy-Intensity Improvements Parameters of Demand. Philosophical Transactions of The Royal Society AMathematical Physical and Engineering Sciences 371. 20120003-20120003.

[56] Duflou JR, De Moor J, Verpoest I, Dewulf W (2009) Environmental Impact Analysis of Composite Use in Car Manufacturing. CIRP Annals - Manufacturing Technology 58:9-12.

[57] Duflou JR, Deng Y, Van Acker K, Dewulf W (2012) Do Fiber-Reinforced Polymer Composites Provide Environmentally Benign Alternatives? A Life-Cycle-Assessment-Based Study. MRS Bulletin 37:374-382.

[58] Song YS, Youn JR, Gutowski TG (2009) Life Cycle Energy Analysis of FiberReinforced Composites. Composites Part A: Applied Science and Manufacturing 40:1257-1265.

[59] Dér A, Kaluza A, Kurle D, Herrmann C, Kara S, Varley R (2018) Life Cycle Engineering of Carbon Fibres for Lightweight Structures. Procedia CIRP 69:4348.

[60] Liu G, Müller DB (2013) Mapping the Global Journey of Anthropogenic Aluminum: A Trade-linked Multilevel Material Flow Analysis. Environmental Science \& Technology 47:11873-11881.

[61] Liu G, Müller DB (2012) Addressing Sustainability in the Aluminum Industry: A Critical Review of Life Cycle Assessments. Journal of Cleaner Production 35:108-117.

[62] Kim H-J, McMillan C, Keoleian GA, Skerlos SJ (2010) Greenhouse Gas Emissions Payback for Lightweighted Vehicles Using Aluminum and High- Strength Steel. Journal of Industrial Ecology 14:929-946.

[63] Mayyas AT, Qattawi A, Mayyas AR, Omar MA (2012) Life Cycle AssessmentBased Selection for a Sustainable Lightweight Body-in-White Design. Energy 39:412-425.

[64] Ellenrieder G, Gänsicke T, Goede M, Herrmann HG (2013) Die Leichtbaustrategien. Leichtbau Der Fahrzeugtechnik, Springer Fachmedien Wiesbaden, Wiesbaden43-118.

[65] Kim HC, Wallington TJ (2013) Life-Cycle Energy and Greenhouse Gas Emission Benefits of Lightweighting in Automobiles: Review and Harmonization. Environmental Science \& Technology 47:6089-6097.

[66] Verbrugge M, Lee T, Krajewski P, Sachdev A, Bjelkengren C, Roth R, Kirchain R (2009) Mass Decompounding and Vehicle Lightweighting. Materials Science Forum 618-619:411-418.

[67] Taub Al, Luo AA (2015) Advanced Lightweight Materials and Manufacturing Processes for Automotive Applications. MRS Bulletin 40:1045-1054

[68] Ehrenberger S, Dieringa H, Friedrich HE (2013) Assessment of Magnesium Components in Vehicle Construction, German Aerospace Centre e.V.

[69] Das S (2011) Life Cycle Assessment of Carbon Fiber-Reinforced Polymer Composites. The International Journal of Life Cycle Assessment 16:268-282.

[70] Suzuki T, Takahashi J (2005) Prediction of Energy Intensity of Carbon Fiber Reinforced Plastics for Mass-Produced Passenger Cars. The Ninth Japan International SAMPE Symposium JISSE-9 14-19. 
[71] Allwood JM, Kong H, Pole N (2012) Sustainable Materials — With Both Eyes Open, UITCambridge.

[72] Modaresi R, Pauliuk S, Lövik AN, Müller DB (2014) Global Carbon Benefits of Material Substitution in Passenger Cars until 2050 and the Impact on the Steel and Aluminum Industries. Environmental Science \& Technology 48:10776- 10784.

[73] Nuss P, Eckelman MJ (2014) Life Cycle Assessment of Metals: A Scientific Synthesis. PLoS One 9:1-12.

[74] Basson E (2015) Steel in the Circular Economy: A Life Cycle Perspective, World- steel Association.

[75] Chubbs S, Steiner B (1998) Life cycle assessment in the steel industry. Environmental Progress 92-95.

[76] ThyssenKrupp (2014) ThyssenKrupp InCar plus.

[77] Kelly JC, Sullivan JL, Burnham A, Elgowainy A (2015) Impacts of Vehicle Weight Reduction via Material Substitution on Life-Cycle Greenhouse Gas Emissions. Environmental Science \& Technology 49:12535-12542.

[78] Hardwick AP, Outteridge T (2016) Vehicle Lightweighting Through the Use of Molybdenum-bearing Advanced High-strength Steels (AHSS). The International Journal of Life Cycle Assessment 21:1616-1623

[79] Nunez P, Jones S (2016) Cradle to Gate: Life Cycle Impact of Primary Alumini- um Production. The International Journal of Life Cycle Assessment 21:15941604

[80] McMillan CA, Keoleian GA (2009) Not All Primary Aluminium is Created Equal: Life Cycle Greenhouse Gas Emissions from 1990 to 2005. Environmental Science \& Technology 43:1571-1577.

[81] Colett JS, Kelly JC, Keoleian GA (2016) Using Nested Average Electricity Allocation Protocols to Characterize Electrical Grids in Life Cycle Assessment. Journal of Industrial Ecology 20:29-41.

[82] Cherubini F, Raugei M, Ulgiati S (2008) LCA of Magnesium Production. Technological Overview and Worldwide Estimation of Environmental Burdens. Resources Conservation and Recycling 52:1093-1100.

[83] Zang JC, Ding W (2016) The Pidgeon Process in China and Its Future. Essential Readings in Magnesium Technology, Springer International Publishing, Cham113-116.

[84] Gao F, Nie Z, Wang Z, Gong X, Zuo T (2009) Life Cycle Assessment of Primary Magnesium Production Using the Pidgeon Process in China. The International Journal of Life Cycle Assessment 14:480-489.

[85] Gao F, Liu Y, Nie ZR, Gong X, Wang Z (2015) Variation Trend and Driving Factors of Greenhouse Gas Emissions from Chinese Magnesium Production. Environmental Science \& Technology 49:12662-12669.

[86] Tharumarajah A, Koltun P (2007) Is There an Environmental Advantage of Using Magnesium Components for Light-Weighting Cars? Journal of Cleaner Production 15:1007-1013.

[87] Anderson J, Jansz A, Steele K, Thistlethwaite P (2004) Green Guide To Composites. Reinforced Plastics 48:18-26.

[88] Swolfs Y (2015) Hybridisation of Self-Reinforced Composites: Modelling and Verifying a Novel Hybrid Concept, KU Leuven.

[89] Lyu MY, Choi TG (2015) Research Trends in Polymer Materials for Use in Lightweight Vehicles. International Journal of Precision Engineering and Manufacturing 16:213-220.

[90] Koronis G, Silva A, Fontul M (2013) Green Composites: A Review of Adequate Materials for Automotive Applications. Composites Part B: Engineering 44:120-127.

[91] Mohanty A, Misra M, Hinrichsen G (2000) Biofibers, Biodegradable Polymers and Biocomposites: An Overview. Macromolecular Materials and Engineering 276:1-24.

[92] Vo Hong N, Pyka G, Wevers M, Goderis B, Van Puyvelde P, Verpoest I, Van Vuure AW (2015) Processing Rigid Wheat Gluten Biocomposites for High Mechanical Performance Composites Part A: Applied Science and Manufactur- ing 79:74-81.

[93] Wheatley A, Warren D, Das S (2013) Development of Low-Cost Carbon Fibre for Automotive Applications. Advanced Composite Materials for Automotive Applications, John Wiley \& Sons Ltd, Chichester, UK51-73.

[94] Mainka H, Täger O, Körner E, Hilfert L, Busse S, Edelmann FT, Herrmann AS (2015) Lignin - An Alternative Precursor for Sustainable and Cost-Effective Automotive Carbon Fiber. Journal of Materials Research and Technology 4:283- 296 .

[95] Morgan P (2005) Carbon Fibers and Their Composites, CRC Press.

[96] Achternbosch M, Bräutigam K-R, Kupsch C, ReBler B, Sardemann G (2003) Analyse der Umweltauswirkungen bei der Herstellung, dem Einsatz und der Entsorgung von CFK-bzw, Aluminiumrumpfkomponenten.

[97] Khalil YF (2017) Eco-Efficient Lightweight Carbon-Fiber Reinforced Polymer for Environmentally Greener Commercial Aviation Industry. Sustainable Production and Consumption 12:16-26.

[98] Koffler C (2013) Life Cycle Assessment of Automotive Lightweighting through Polymers under US Boundary Conditions. The International Journal of Life Cycle Assessment 19:538-545.

[99] Witik RA, Payet J, Michaud V, Ludwig C, Månson JAE (2011) Assessing the Life Cycle Costs and Environmental Performance of Lightweight Materials in Automobile Applications. Composites Part A: Applied Science and Manufacturing 42:1694-1709

[100] Grand View Natural Research (2016) Fiber Composites Market Analysis.

[101] Deng Y (2014) Life Cycle Assessment of Biobased Fibre-Reinforced Polymer Composites, KU Leuven.

[102] Dicker MPM, Duckworth PF, Baker AB, Francois G, Hazzard MK, Weaver PM (2014) Green Composites: A Review of Material Attributes and Complemen- tary Applications. Composites Part A: Applied Science and Manufacturing 56:280289.

[103] Duflou JR, Yelin D, Van Acker K, Dewulf W (2014) Comparative Impact Assessment for Flax Fibre versus Conventional Glass Fibre Reinforced Composites: Are Bio-Based Reinforcement Materials the Way to Go? CIRP Annals Manufacturing Technology 63:45-48.
[104] Prabhakaran S, Krishnaraj V, Senthil Kumar M, Zitoune R (2014) Sound and Vibration Damping Properties of Flax Fiber Reinforced Composites. Procedia Engineering 97:573-581.

[105] Stamboulis A, Baillie CA, Garkhail SK, Van Melick HGH, Peijs T (2000) Environmental Durability of Flax Fibres and Their Composites Based on Polypropylene Matrix. Applied Composite Materials 7:273-294.

[106] Boland CS, De Kleine R, Keoleian GA, Lee EC, Kim HC, Wallington TJ (2015) Life Cycle Impacts of Natural Fiber Composites for Automotive Applications: Effects of Renewable Energy Content and Lightweighting. Journal of Industrial Ecology 20:179-189.

[107] Gao C, Yu L, Liu H, Chen L (2012) Development of Self-Reinforced Polymer Composites. Progress in Polymer Science 37:767-780.

[108] Delogu M, Zanchi L, Maltese S, Bonoli A, Pierini M (2016) Environmental and Economic Life Cycle Assessment of a Lightweight Solution for an Automotive Component: A Comparison Between Talc-Filled and Hollow Glass Micro- spheresReinforced Polymer Composites. Journal of Cleaner Production 139:548-560.

[109] Ashby MF, Cebon D (1993) Materials Selection in Mechanical Design1-9. Le J Phys IV. 03

[110] Ashby MF (2013) Chapter 15 - Material Profiles. Materials and the Environment 459-595.

[111] Jahan A, Ismail MY, Sapuan SM, Mustapha F (2010) Material Screening and Choosing Methods - A Review. Materials and Design 31:696-705.

[112] Wanner A (2010) Minimum-Weight Materials Selection for Limited Available Space. Materials and Design 31:2834-2839.

[113] Corona A, Madsen B, Hauschild MZ, Birkved M (2016) Natural Fibre Selection for Composite Eco-Design. CIRP Annals — Manufacturing Technology 65:13-16.

[114] Shah DU (2014) Natural Fibre Composites: Comprehensive Ashby-Type Mate- rials Selection Charts. Materials and Design 62:21-31.

[115] Ermolaeva NS, Castro MBG, Kandachar PV (2004) Materials Selection for an Automotive Structure by Integrating Structural Optimization with Environmental Impact Assessment. Materials and Design 25:689-698.

[116] He Y, Huang T, Wang Y, Nie Y, Li Y, Wang Y (2017) A New Lightweight Design Method Integrating Shape Optimization with Life Cycle Assessment for Extrusion Dies. Journal of Cleaner Production 150:47-57.

[117] Mayyas AT, Qattawi A, Mayyas AR, Omar M (2013) Quantifiable Measures of Sustainability: A Case Study of Materials Selection for Eco-Lightweight AutoBodies. Journal of Cleaner Production 40:177-189.

[118] Sakundarini N, Taha Z, Abdul-Rashid SH, Ghazila RAR (2013) Optimal MultiMaterial Selection for Lightweight Design of Automotive Body Assembly Incorporating Recyclability. Materials and Design 50:846-857.

[119] Poulikidou S, Schneider C, Björklund A, Kazemahvazi S, Wennhage P, Zenkert D (2015) A Material Selection Approach to Evaluate Material Substitution for Minimizing the Life Cycle Environmental Impact of Vehicles. Materials and Design 83:704-712.

[120] Ribeiro I, Peças P, Silva A, Henriques E (2008) Life Cycle Engineering Methodology Applied to Material Selection, a Fender Case Study. Journal of Cleaner Production 16:1887-1899.

[121] Le Duigou J, Gulbrandsen-Dahl S, Vallet F, Söderberg R, Eynard B, Perry N (2016) Optimization and Lifecycle Engineering for Design and Manufacture of Recycled Aluminium Parts. CIRP Annals - Manufacturing Technology 65:149152.

[122] Giudice F, La Rosa G, Risitano A (2005) Materials Selection in the Life-Cycle Design Process: A Method to Integrate Mechanical and Environmental Performances in Optimal Choice. Materials and Design 26:9-20.

[123] Grujicic M, Sellappan V, He T, Seyr N, Obieglo A, Erdmann M, Holzleitner J (2009) Total Life Cycle-Based Materials Selection for Polymer Metal Hybrid Body-in-White Automotive Components. Journal of Materials Engineering and Performance 18:111-128.

[124] Kaiser R, Wicht D, Vielhaber M (2016) Integration of a Systematic Material Selection into the Dynamic Develeopment Process of Vehicle Structure Parts. DS 84: Proceedings of the DESIGN 2016 14th International Design Conference 261-270.

[125] Sun X, Liu J (2017) Life Cycle Assessment-Based Selection of a Sustainable Lightweight Automotive Engine Hood Design. The International Journal of Life Cycle Assessment.

[126] Jeya Girubha R, Vinodh S (2012) Application of Fuzzy VIKOR and Environmental Impact Analysis for Material Selection of an Automotive Component Materials and Design 37:478-486.

[127] Fleischer J, Lanza G, Tarisai P, Möhring H, Teti R, Caggiano A (2018) Composite Materials Parts Manufacturing. CIRP Annals - Manufacturing Technology 67(2).

[128] Beiter P, Groche P (2011) On the Development of Novel Light Weight Profiles for Automotive Industries by Roll Forming of Tailor Rolled Blanks. Key Engineering Materials 473:45-52.

[129] Ingarao G, Di Lorenzo R, Micari F (2011) Sustainability Issues in Sheet Meta Forming Processes: An Overview. Journal of Cleaner Production 19:337-347.

[130] Broch F, Warsen J, Krinke S (2015) Implementing Life Cycle Engineering in Automotive Development as a Helpful Management Tool to Support Design for Environment. in Sonnemann G, Margni M, (Eds.) Life Cycle Manag, Spring-er, pp. 319-329.

[131] Raugei M, El Fakir O, Wang L, Lin J, Morrey D (2014) Life Cycle Assessment of the Potential Environmental Benefits of a Novel Hot Forming Process in Automotive Manufacturing. Journal of Cleaner Production 83:80-86.

[132] Yanagimoto J, Ikeuchi K (2012) Sheet Forming Process of Carbon Fiber Reinforced Plastics for Lightweight Parts. CIRP Annals - Manufacturing Technology 61:247-250.

[133] Landgrebe D, Kräusel V, Rautenstrauch A, Albert A, Wertheim R (2016) EnergyEfficiency in a Hybrid Process of Sheet Metal Forming and Polymer Injection Moulding. Procedia CIRP 40:109-114.

[134] Kleiner M, Chatti S, Klaus A (2006) Metal Forming Techniques for Lightweight Construction. Journal of Materials Processing Technology 177:2-7. 
[135] Ingarao G, Ambrogio G, Gagliardi F, Di Lorenzo R (2012) A Sustainability Point of View on Sheet Metal Forming Operations: Material Wasting and Energy Consumption in Incremental Forming and Stamping Processes. Journal of Cleaner Production 29-30:255-268

[136] Ambrogio G, Filice L, Gagliardi F (2012) Formability of Lightweight Alloys by Hot Incremental Sheet Forming. Materials and Design 34:501-508.

[137] Shishoo R (2012) The Global Textile and Clothing Industry, Woodhead Publish-

[138] Silva FJG, Ferreira F, Ribeiro MCS, Castro ACM, Castro MRA, Dinis ML, Fiúza A (2014) Optimising the Energy Consumption on Pultrusion Process. Composites Part B: Engineering 57:13-20.

[139] Hohmann A, Albrecht S, Lindner JP, Voringer B, Wehner D, Drechsler K, Leistner P (2018) Resource efficiency and environmental impact of fiber reinforced plastic processing technologies. Production Engineering 12:405- 417.

[140] Ogale A, Mitschang P (2004) Tailoring of Textile Preforms for Fibre-Reinforced Polymer Composites. Journal of Industrial Textiles 34:77-96.

[141] Liebsch A, Kupfer R, Defranceski A, Rösler B, Janik J, Gude M (2017) Automated Preforming of Braided Hoses Made of Thermoplast-Glass Fiber Hybrid Yarns. Procedia CIRP 66:57-61

[142] Oliveux G, Dandy LO, Leeke GA (2015) Current Status of Recycling of Fibre Reinforced Polymers: Review of Technologies, Reuse and Resulting Properties. Progress in Materials Science 72:61-99.

[143] Kropka M, Muehlbacher M, Neumeyer T, Altstaedt V (2017) From UD-Tape to Final Part - A Comprehensive Approach Towards Thermoplastic Composites. Procedia CIRP 66:96-100.

[144] Brecher C, Schmitt R, Lindner F, Peters T, Emonts M, Böckmann MG (2016) Increasing Cost and Eco Efficiency for Selective Tape Placement and Forming by Adaptive Process Design. Procedia CIRP 57:769-774.

[145] Helou M, Kara S (2017) Design, Analysis and Manufacturing of Lattice Structures. International Journal of Computer Integrated Manufacturing.

[146] Kellens K, Mertens R, Paraskevas D, Dewulf W, Duflou JR (2017) Environmental Impact of Additive Manufacturing Processes: Does AM Contribute to a More Sustainable Way of Part Manufacturing? Procedia CIRP 61:582-587.

[147] Kellens K, Baumers M, Gutowski TG, Flanagan W, Lifset R, Duflou JR (2017) Environmental Dimensions of Additive Manufacturing: Mapping Application Domains and Their Environmental Implications. Journal of Industrial Ecology 21:1-20

[148] Huang R, Riddle M, Graziano D, Warren J, Das S, Nimbalkar S, Cresko J, Masanet E (2016) Energy and Emissions Saving Potential of Additive Manufacturing: The Case of Lightweight Aircraft Components. Journal of Cleaner Production 135:1559-1570.

[149] Lutter-Günther M, Gebbe C, Kamps T, Seidel C, Reinhart G (2018) Powder recycling in laser beam melting: strategies, consumption modeling and influence on resource efficiency. Production Engineering 12:377-389.

[150] Gebbe C, Lutter-Günther M, Greiff B, Glasschröder J, Reinhart G (2015) Measurement of the Resource Consumption of a Selective Laser Melting Process. Applied Mechanics and Materials 805:205-212.

[151] Kellens K, Yasa E, Renaldi. Dewulf W, Kruth J, Duflou J (2011) Energy and Resource Efficiency of SLS/SLM Processes. Solid Freeform Fabrication Sympo- sium 1-16.

[152] Schönemann M, Schmidt C, Herrmann C, Thiede S (2016) Multi-Level Model- ing and Simulation of Manufacturing Systems for Lightweight Automotive Components. Procedia CIRP 41:1049-1054.

[153] Ribeiro I, Kaufmann J, Schmidt A, Peças P, Henriques E, Götze U (2016) Fostering Selection of Sustainable Manufacturing Technologies - A Case Study Involving Product Design, Supply Chain and Life Cycle Performance. Journal of Cleaner Production 112:3306-3319.

[154] Fanghänel C, Rautenstrauch A, Symmank C, Katzenberger J, Putz M, Kräusel V, Götze U, Awiszus B (2015) Multidimensional Analysis of Process Chains Regarding the Resource-Efficient Manufacturing of Hybrid Structures. Procedia CIRP 26:595-600.

[155] Lindner F, Schmitt R (2015) Goal-Oriented Life Cycle Investigations for Composite Manufacturing Chains. Procedia CIRP 29:438-443.

[156] Audi AG (2011) Life Cycle Assessment Audi A6Www.Audi.Com/Content/Dam/ Com/EN/Corporate-Responsibility/Product/Audi_a6_life_cycle_assessment. Pdf.

[157] Koffler C, Rohde-Brandenburger K (2010) On the Calculation of Fuel Savings Through Lightweight Design in Automotive Life Cycle Assessments. The International Journal of Life Cycle Assessment 15:128-135.

[158] Kim HC, Wallington TJ (2013) Life Cycle Assessment of Vehicle Lightweight- ing: A Physics-Based Model to Estimate Use-Phase Fuel Consumption of Electrified Vehicles. Environmental Science \& Technology 50:11226-11233.

[159] Weymar E, Finkbeiner M (2016) Statistical Analysis of Empirical Lifetime Mileage Data for Automotive LCA. Int J LCA 21:215-223.

[160] U.S. Environmental Protection Agency (2012) EPA and NHTSA Set Standards to Reduce Greenhouse Gases and Improve Fuel Economy for Model Years 2017-2025 Cars and Light Trucks1-10.

[161] Delogu M, Pero F, Del Pierini M (2016) Lightweight Design Solutions in the Automotive Field: Environmental Modelling Based on Fuel Reduction Value Applied to Diesel Turbocharged Vehicles. Sustainability 8.

[162] Pandian S, Gokhale S, Ghoshal AK (2009) Evaluating Effects of Traffic and Vehicle Characteristics on Vehicular Emissions Near Traffic Intersections. Transportation Research Part D: Transport and Environment 14:180-196.

[163] Fiebig M, Wiartalla A, Holderbaum B, Kiesow S (2014) Particulate Emissions from Diesel Engines: Correlation Between Engine Technology and Emissions. Journal of Occupational Medicine and Toxicology 9:6.

[164] Del Pero F, Delogu M, Pierini M (2017) The Effect of Lightweighting in Automotive LCA Perspective: Estimation of Mass-Induced Fuel Consumption Reduction for Gasoline Turbocharged Vehicles. Journal of Cleaner Production 154:566-577.
[165] Alonso E, Lee TM, Bjelkengren C, Roth R, Kirchain RE (2012) Evaluating the Potential for Secondary Mass Savings in Vehicle Lightweighting. Environmen- tal Science \& Technology 46:2893-2901

[166] Das S, Graziano D, Upadhyayula VKK, Masanet E, Riddle M, Cresko J (2016) Vehicle Lightweighting Energy Use Impacts in U.S. Light-Duty Vehicle Fleet. Sustainable Materials and Technologies 8:5-13.

[167] Duce A, Del Egede P, Öhlschläger G, Dettmer T, Althaus H-J, Bütler T, Szczechowicz E (2013) Guidelines for the LCA of Electric Vehicles, European Union.

[168] Ellingsen LA-W, Singh B, Strømman AH (2016) The Size and Range Effect: Lifecycle Greenhouse Gas Emissions of Electric Vehicles. Environmental Research Letters 11:054010.

[169] Hawkins TR, Gausen OM, Strömman AH (2012) Environmental Impacts of Hybrid and Electric Vehicles - A Review. The International Journal of Life Cycle Assessment 17:997-1014.

[170] Hofer J, Wilhelm E, Schenler W (2014) Comparing the Mass, Energy, and Cost Effects of Lightweighting in Conventional and Electric Passenger Vehicles. Sustainable Development of Energy Water and Environment Systems 2:284295

[171] Grunditz EA, Thiringer T (2016) Performance Analysis of Current BEVs Based on a Comprehensive Review of Specifications. IEEE Transactions on Transportation Electrification 2:270-289.

[172] Campanari S, Manzolini G, Garcia de la Iglesia F (2009) Energy Analysis of Electric Vehicles Using Batteries or Fuel Cells Through Well-to-wheel Driving Cycle Simulations. Journal of Power Sources 186:464-477.

[173] Egede P, Dettmer T, Herrmann C, Kara S (2015) Life Cycle Assessment of Electric Vehicles - A Framework to Consider Influencing Factors. Procedia CIRP 29:233-238

[174] Shaw J, Kuriyama Y, Lambriks M (2011) Achieving a Lightweight and Stee/Intensive Body Structure for Alternative Powertrains, SAE International.

[175] Delogu M, Zanchi L, Dattilo CA, Pierini M (2017) Innovative Composites and Hybrid Materials for Electric Vehicles Lightweight Design in a Sustainability perspective. Materials Today Communications 13:192-209.

[176] Luk JM, Kim HC, De Kleine R, Wallington TJ, MacLean HL (2017) Review of the Fuel Saving, Life Cycle GHG Emission, and Ownership Cost Impacts of Lightweighting Vehicles with Different Powertrains. Environmental Science \& Technology 51:8215-8228

[177] Luedeke T, Vielhaber M (2014) Holistic Approach for Secondary Weight Improvements. Procedia CIRP 21:218-223.

[178] Liebl J, Lederer M, Rohde-Brandenburger K, Biermann J-W, Roth M, Schäfer H (2014) Energiemanagement im Kraftfahrzeug.

[179] Lewis AM, Kelly JC, Keoleian GA (2014) Vehicle Lightweighting vs. Electrification: Life Cycle Energy and GHG Emissions Results for Diverse Powertrain Vehicles. Applied Energy 126:13-20.

[180] González Palencia JC, Furubayashi T, Nakata T (2012) Energy Use and $\mathrm{CO}_{2}$ Emissions Reduction Potential in Passenger Car Fleet Using Zero Emission Vehicles and Lightweight Materials. Energy 48:548-565.

[181] González Palencia JC, Furubayashi T, Nakata T (2014) Techno-Economic Assessment of Lightweight and Zero Emission Vehicles Deployment in the Passenger Car Fleet of Developing Countries. Applied Energy 123:129-142.

[182] González Palencia JC, Sakamaki T, Araki M, Shiga S (2015) Impact of Powertrain Electrification, Vehicle Size Reduction and Lightweight Materials Substitution on Energy Use, $\mathrm{CO}_{2}$ Emissions and Cost of a Passenger Light-Duty Vehicle Fleet. Energy 93

[183] ICAO (2016) ICAO Environmental Report250.

[184] de Oliveira Fernandes Lopes JV (2010) Life Cycle Assessment of the Airbus A 330- 200 Aircraft Assessment, Universidade Técnica de Lisboa: 140

[185] Johanning A, Scholz D (2015) Comparison of the potential environmental impact improvements of futureaircraft concepts using life cycle assessment. CEAS 2015, $1-16$.

[186] Kara S, Manmek S (2009) Composites: Calculating Their Embodied Energy, Department of Employment, Economic Development and Innovation (DEEDI), the State of Queensland, Australia.

[187] Geyer R, Kuczenski B, Zink T, Henderson A (2016) Common Misconceptions About Recycling. Journal of Industrial Ecology 20:1010-1017.

[188] Gutowski TG, Allwood JM, Herrmann C, Sahni S (2013) A Global Assessment of Manufacturing: Economic Development, Energy Use, Carbon Emissions, and the Potential for Energy Efficiency and Materials Recycling. Annual Review of Environment and Resources 38:81-106

[189] Soo VK, Compston P, Subic A, Doolan M (2014) The Impact of Different Joining Decisions for Lightweight Materials on Life Cycle Assessment. AutoCRC 3rd Technical Conference.

[190] Fleischer J, Lanza G, Tarisai P, Möhring H, Teti R, Caggiano A (2018) Composite Materials Parts Manufacturing. CIRP Ann Manuf Technol 00.

[191] European Parliament and Council, (2000), ELV Directive.

[192] Ehrenberger S, Friedrich HE (2013) Life-Cycle Assessment of the Recycling of Magnesium Vehicle Components. JOM 65:1303-1309.

[193] Schmidt W-P, Dahlqvist E, Finkbeiner M, Krinke S, Lazzari S, Oschmann D, Pichon S, Thiel C (2004) Life Cycle Assessment of Lightweight and End-of-Life Scenarios for Generic Compact Class Passenger Vehicles. The International Journal of Life Cycle Assessment 9:405-416.

[194] Dalmijn WL, De Jong TPR (2007) The Development of Vehicle Recycling in Europe: Sorting, Shredding, and Separation. JOM 59:52-56.

[195] Mativenga PT, Shuaib NA, Howarth J, Pestalozzi F, Woidasky J (2016) High Voltage Fragmentation and Mechanical Recycling of Glass Fibre Thermoset Composite. CIRP Annals - Manufacturing Technology 65:45-48.

[196] Pimenta S, Pinho ST (2011) Recycling Carbon Fibre Reinforced Polymers for Structural Applications: Technology Review and Market Outlook. Waste Management 31:378-392.

[197] Witik RA, Teuscher R, Michaud V, Ludwig C, Månson JAE (2013) Carbon Fibre Reinforced Composite Waste: An Environmental Assessment of Recycling, Energy Recovery and Landfilling. Composites Part A: Applied Science and Manufacturing 49:89-99. 
[198] Haas W, Krausmann F, Wiedenhofer D, Heinz M (2015) How Circular is the Global Economy?: An Assessment of Material Flows, Waste Production, and Recycling in the European Union and the World in 2005. Journal of Industrial Ecology 19:765-777.

[199] Paraskevas D, Kellens K, Renal Dewulf W, Duflou JR (2013) Closed and Open Loop Recycling of Aluminium: A Life Cycle Assessment Perspective. The 11th Global Conference on Sustainable Manufacturing 302-307.

[200] Ohno H, Matsubae K, Nakajima K, Nakamura S, Nagasaka T (2014) Unintentional Flow of Alloying Elements in Steel During Recycling of End-of-Life Vehicles. Journal of Industrial Ecology 18:242-253.

[201] Ohno H, Matsubae K, Nakajima K, Kondo Y, Nakamura S, Nagasaka T (2015) Toward the Efficient Recycling of Alloying Elements from End of Life Vehicle Stee Scrap. Resources Conservation and Recycling 100:11-20.

[202] Papadakis L, Schiel M, Vassilou V, Loizou A, Dilger K (2014) Adhesive Bonding of Attachments on Alternate Car Shell Surfaces in Automotive Final Assembly Lines. Procedia CIRP 18:180-185.

[203] Meschut G, Janzen V, Olfermann T (2014) Innovative and Highly Productive Joining Technologies for Multi-Material Lightweight Car Body Structures. Journal of Materials Engineering and Performance 23:1515-1523.

[204] World Steel Association (2014) World Steel in Figures 2014, World Stee Association (WSA), Brussels.

[205] Cui J, Roven HJ (2010) Recycling of Automotive Aluminum. Transactions of Nonferrous Metals Society of China 20:2057-2063. (English Ed.).

[206] Duflou JR, Tekkaya AE, Haase M, Welo T, Vanmeensel K, Kellens K, Dewulf W, Paraskevas D (2015) Environmental Assessment of Solid State Recycling Routes for Aluminium Alloys: Can Solid State Processes Significantly Reduce the Environmental Impact of Aluminium Recycling? CIRP Annals - Manufacturing Technology 64:37-40.

[207] Pickering SJ (2006) Recycling Technologies for Thermoset Composite Mate- rials - Current Status. Composites Part A: Applied Science and Manufacturing 37:1206-1215.

[208] Yang Y, Boom R, Irion B, van Heerden D-J, Kuiper P, de Wit H (2012) Recycling of Composite Materials. Chemical Engineering and Processing - Process Intensification 51:53-68.

[209] Shuaib NA, Mativenga PT (2015) Energy Demand in Mechanical Recycling of Glass Fibre Reinforced Thermoset Plastic Composites. Journal of Cleaner Production 120:198-206.

[210] Howarth J, Mareddy SSR, Mativenga PT (2014) Energy Intensity and Environmental Analysis of Mechanical Recycling of Carbon Fibre Composite. Journal of Cleaner Production 81:46-50.

[211] Li X, Bai R, McKechnie J (2015) Environmental and Financial Performance of Mechanical Recycling of Carbon Fibre Reinforced Polymers and Comparison with Conventional Disposal Routes. Journal of Cleaner Production 127:451- 460.

[212] Longana ML, Ong N, Yu HN, Potter KD (2016) Multiple Closed Loop Recycling of Carbon Fibre Composites With the HiPerDiF (High Performance Discontinuous Fibre) Method. Composite Structures 153:271-277.

[213] Meng F, McKechnie J, Turner TA, Pickering SJ (2017) Energy and Environmen-tal Assessment and Reuse of Fluidised Bed Recycled Carbon Fibres. Composites Part A: Applied Science and Manufacturing 100:206-214

[214] Shuaib NA, Mativenga PT (2017) Carbon Footprint Analysis of Fibre Reinforced Composite Recycling Processes. Procedia Manufacturing 7:183-190.

[215] Prinçaud M, Aymonier C, Loppinet-Serani A, Perry N, Sonnemann G (2014) Environmental Feasibility of the Recycling of Carbon Fibers from CFRPs by Solvolysis Using Supercritical Water. ACS Sustainable Chemistry Engineering2:1498-1502.

[216] Liu Y, Farnsworth M, Tiwari A (2017) A Review of Optimisation Techniques Used in the Composite Recycling Area: State-of-the-Art and Steps Towards a Research Agenda. Journal of Cleaner Production 140:1775-1781.

[217] Rybicka J, Tiwari A, Leeke GA (2016) Technology Readiness Level Assessment of Composites Recycling Technologies. Journal of Cleaner Production 112:10011012.

[218] Pimenta S, Pinho ST (2012) The Effect of Recycling on the Mechanical Response of Carbon Fibres and Their Composites. Composite Structures 94:3669-3684.

[219] McMillan CA, Moore MR, Keoleian GA, Bulkley JW (2010) Quantifying U.S. Aluminum in-use Stocks and Their Relationship with Economic Output. Ecological Economics 69:2606-2613.

[220] McMillan CA, Skerlos SJ, Keoleian GA (2012) Evaluation of the Metals Indus- try's Position on Recycling and its Implications for Environmental Emissions. Journal of Industrial Ecology 16:324-333.

[221] Lefeuvre A, Garnier S, Jacquemin L, Pillain B, Sonnemann G (2017) Anticipat- ing in-use Stocks of Carbon Fiber Reinforced Polymers and Related Waste Flows Generated by the Commercial Aeronautical Sector Until 2050. Resources Conservation and Recycling 125:264-272.

[222] Inghels D, Dullaert W, Raa B, Walther G (2016) Influence of Composition, Amount and Life Span of Passenger Cars on end-of-life Vehicles Waste in
Belgium: A System Dynamics Approach. Transportation Research Part A: Policy and Practice 91:80-104.

[223] Frees N (2008) Crediting Aluminium Recycling in LCA by Demand or by Disposal. The International Journal of Life Cycle Assessment 13:212-218.

[224] Rybicka J, Tiwari A, Alvarez Del Campo P, Howarth J (2015) Capturing Composites Manufacturing Waste Flows Through Process Mapping. Journal of Cleaner Production 91:251-261.

[225] Gala AB, Raugei M, Fullana-i-Palmer P (2015) Introducing a New Method for Calculating the Environmental Credits of End-of-Life Material Recovery in Calculating the Environmental Credits of End-of-Life Material Recovery in Attribu.

[226] Castro MBG, Remmerswaal JAM, Reuter MA, Boin UJM (2004) A Thermody namic Approach to the Compatibility of Materials Combinations for Recy- cling Resources Conservation and Recycling 43:1-19.

[227] Keivanpour S, Ait Kadi D, Mascle C (2017) End-of-Life Aircraft Treatment in the Context of Sustainable Development, Lean Management, and Global Business. International Journal of Sustainable Transportation 11:357-380.

[228] Dong PAV, Azzaro-Pantel C, Boix M, Jacquemin L, Cadène AL (2016) A Bicriteria Optimisation Approach for Waste Management of Carbon Fibre Reinforced Polymers Used in Aerospace Applications: Application to the Case Study of France. Waste and Biomass Valorization 1-22.

[229] Pompidou S, Prinçaud M, Perry N, Leray D (2012) Recycling of Carbon Fiber Identification of Bases for a Synergy Between Recyclers and Designers. ASME 2012 3:551-560.

[230] Kellens K, Dewulf W, Overcash M, Hauschild MZ, Duflou JR (2012) Methodology for Systematic Analysis and Improvement of Manufacturing Unit Process Life-Cycle Inventory (UPLCI)—CO2PE! Initiative (Cooperative Effort on Process Emissions in Manufacturing). Part 1: Methodology Description. The International Journal of Life Cycle Assessment 17:69-78.

[231] Wernet G, Bauer C, Steubing B, Reinhard J, Moreno-Ruiz E, Weidema B (2016) The Ecoinvent Database Version 3 (Part I): Overview and Methodology. The International Journal of Life Cycle Assessment 21:1218-1230.

[232] Nielsen CB, Larsen PG, Fitzgerald J, Woodcock J, Peleska J (2015) Systems of Systems Engineering. ACM Computing Surveys 48:1-41.

[233] Lukasik SJ (1998) Systems, Systems of Systems, and the Education of Engineers. Artificial Intelligence $55-60$.

[234] Joost WJ (2012) Reducing Vehicle Weight and Improving U.S. Energy Efficiency Using Integrated Computational Materials Engineering. JOM 64:1032-1038.

[235] Hauschild MZ (2015) Better - But is It Good Enough? On the Need to Consider Both Eco-Efficiency and Eco-Effectiveness to Gauge Industrial Sustainability. Procedia CIRP 29:1-7.

[236] Bjørn A, Hauschild MZ (2015) Introducing Carrying Capacity-based Normalisation in LCA: Framework and Development of References at Midpoint Level. The International Journal of Life Cycle Assessment 20:1005-1018.

[237] Tuomisto HL, Hodge ID, Riordan P, MacDonald DW (2012) Exploring a Safe Operating Approach to Weighting in Life Cycle Impact Assessment - A Case Study of Organic, Conventional and Integrated Farming Systems. Journal of Cleaner Production 37:147-153.

[238] Ryberg MW, Owsianiak M, Richardson K, Hauschild MZ (2016) Challenges in Implementing a Planetary Boundaries Based Life-Cycle Impact Assessment Methodology. Journal of Cleaner Production 139:450-459

[239] Whitefoot KS, Grimes-Casey HG, Girata CE, Morrow WR, Winebrake JJ, Keoleian GA. Skerlos SJ (2011) Consequential Life Cycle Assessment With MarketDriven Design. Journal of Industrial Ecology 15:726-742.

[240] Whitefoot KS, Skerlos SJ (2012) Design Incentives to Increase Vehicle Size Created From the U.S. Footprint-Based Fuel Economy Standards. Energy Policy 41:402-411.

[241] Whitefoot KS, Fowlie ML, Skerlos SJ (2017) Compliance by Design: Influence of Acceleration Trade-offs on $\mathrm{CO}_{2}$ Emissions and Costs of Fuel Economy and Greenhouse Gas Regulations. Environmental Science \& Technology 51:1030710315.

[242] European Commission - Joint Research Centre - Institute for Environment and Sustainability (2010) International Reference Life Cycle Data System (ILCD) Handbook - General Guide for Life Cycle Assessment - Detailed Guidance.

[243] Umeda Y, Takata S, Kimura F, Tomiyama T, Sutherland JW, Kara S, Herrmann C Duflou JR (2012) Toward Integrated Product and Process Life Cycle Planning — An Environmental Perspective. CIRP Annals - Manufacturing Technology 61:681702.

[244] Millet D, Bistagnino L, Lanzavecchia C, Camous R, Poldma T (2006) Does the Potential of the Use of LCA Match the Design Team Needs? Journal of Cleaner Production 15:335-346.

[245] Keim D, Andrienko G, Fekete J, Carsten G, Melan G (2008) Visual Analytics: Definition Process, and Challenges. Information Visualization - Human-Centered Issues and Perspectives, 154-175.

[246] Kaluza A, Gellrich S, Cerdas F, Thiede S, Herrmann C (2018) Life Cycle Engineering Based on Visual Analytics. Procedia CIRP 69:37-42 